\title{
CONTRACT DURATION AND INDEXATION IN A PERIOD OF REAL AND NOMINAL UNCERTAINTY
}

\author{
LOUIS N. CHRISTOFIDES \\ CHEN PENG
}

CESIFO WORKING PAPER NO. 994

CATEGORY 4: LABOUR MARKETS

JULY 2003

Presented at CESifo Conference on Employment And Social Protection, May 2003

An electronic version of the paper may be downloaded

- from the SSRN website: www.SSRN.com

- from the CESifo website: www.CESifo.de 


\title{
CONTRACT DURATION AND INDEXATION IN A PERIOD OF REAL AND NOMINAL UNCERTAINTY
}

\begin{abstract}
A sample of 11885 wage agreements, reached in the Canadian unionized sector during 19762000, a period of high as well as exceptionally low inflation and substantial fluctuations in nominal and real uncertainty, is used to study the determinants of key provisions of contracts such as their duration and indexation clauses. Econometric techniques, which account for the interaction between duration and indexation, as well as the latent nature of the elasticity of indexation are used. Results obtained suggest that expected inflation, nominal and real uncertainty account for most of the secular and cyclical changes in contract provisions.
\end{abstract}

JEL Code: E31, J41 J50.

Keywords: contract duration, indexation, nominal, real uncertainty.

\author{
Louis Christofides \\ Department of Economics \\ University of Cyprus \\ Kallipoleos 75 \\ P.O.Box 20537 \\ 1678 Nicosia \\ Cyprus \\ louis.christofides@ucy.ac.cy
}

\author{
Chen Peng \\ Department of Economics \\ University of Guelph \\ Guelph, ON N1G 2W1 \\ Canada
}

We thank M. Legault, Human Resources Development Canada, for the data and the Social Sciences and Humanities Research Council of Canada for financial support. 


\section{Introduction}

While inflation was relatively high during the 1970s and 1980s, a number of theoretical and empirical studies examined the determinants of key features of collective bargaining agreements, such as contract duration and cost-ofliving-allowance (COLA) clauses. These studies identified a number of important forces that affect these variables. To begin with, contract duration and indexation are determined simultaneously, sometimes in theoretical contexts that involve bargaining. Both variables are influenced by probability beliefs about future values of relevant variables. Prominent among these variables are price inflation and real shocks. Also critical are the parties' attitudes to risk, their relative bargaining strength, circumstances unique to the firm and the union (product and local labour market conditions and how net incomes from other sources might be affected by the state of nature), and the cost of negotiation generally.

The duration of wage contracts and their indexation provisions are important variables, not only because they are the outcomes of optimising actions by labour market agents, but also because they affect the dynamic response of the macro economy to various shocks. Extant theoretical treatments of these contractual provisions are complex and extensive, ${ }^{1}$ but the methodological approaches used lead to different predictions regarding the role of uncertainty. Gray's $(1976,1978)$ macroeconomic work suggests that real and nominal uncertainty should shorten contract duration and that their relative

\footnotetext{
${ }^{1}$ See Shavell (1976), Gray (1976, 1978), Azariadis (1978), Canzoneri (1980), Dye (1985), Card (1986), Ehrenberg, Danziger and San (1983, 1984), Danziger (1988), Murphy (1992), and Barcena-Ruiz and Campo (2000).
} 
significance will determine the optimal degree of indexation - it will be less than unity if real shocks are present. Shavell (1976) and Ehrenberg, Danziger and San $(1983,1984)$ shift the focus to the microeconomic level and to efficient risk-sharing; Danziger (1988) uses the implicit-contracts approach. Depending on the value of parameters, these microeconomic approaches suggest that real and nominal uncertainty can have a variety of effects on contract duration and indexation. Since no central planner imposes Gray's optimality criterion, the relevance of her work for pair-specific outcomes in North America is unclear. Restricting attention to the microeconomic approaches reduces the richness of effects that empirical work might seek, but does not remove the inherent ambiguities. A role remains for inductive work which, by establishing the qualitative role of variables, may provide information on parameters and guide future theoretical endeavours.

At the empirical level, a number of issues remain unresolved or unexplored and hence the dialogue between theory and empirical evidence remains incomplete. $^{2}$ Studies of the role of nominal uncertainty by Christofides and Wilton (1983), Christofides (1990), Murphy (1992, 2000), Rich and Tracy (2000), and Vroman (1989), suggest that nominal uncertainty reduces contract duration, while those by Bils (1990) and Wallace and Blanco (1991) report no effect. Real uncertainty has not been studied as extensively: Murphy (2000) concludes that aggregate real uncertainty lengthens contracts, Kanago (1998) reports a negative, significant, effect on contract duration from rela-

\footnotetext{
${ }^{2}$ Referring to their extensive attempt to check the efficient risk-sharing model against the data, Ehrenberg, Danziger and San (1984, p. 242) conclude that '... the results ... were ... mixed and did not provide strong support for the models.'
} 
tive uncertainty, and Rich and Tracy (2000) suggest that aggregate supply (i.e. real) uncertainty reduces contract duration. Research concerning the role of uncertainty on indexation is less voluminous and not as recent. Ehrenberg, Danziger and San $(1983,1984)$ find that real (industry) shocks affect positively the incidence and intensity of COLA clauses but have a statistically weaker, positive, effect on contract duration. They note that inflation uncertainty has a statistically significant, positive, effect only on the intensity of indexation. The more recent US study by Rich and Tracy (2000) deals with whether COLA clauses are chosen at all, rather than their strength. It reports no significant effect of uncertainty on COLA incidence but all types of uncertainty reduce contract duration. Another recent study by Murphy (2000) concludes that inflation uncertainty reduces contract length but does not significantly affect the probability that a COLA clause will be included in a contract. Thus, considerable diversity exists in the empirical literature concerning the role of nominal and real uncertainty. Mixed findings are also reported about the expected inflation rate itself, a variable whose theoretical role has been discussed at length. Gray (1978, note 3, p. 3) and Ehrenberg, Danziger and San (1984, Table 1, row 7) argue that fully anticipated inflation should have no effect on indexation. A role for expected inflation can be generated in more complex models (Ehrenberg, Danziger and San, 1984, pp. 224-225) and most empirical studies control for this variable.

To some extent, the empirical ambiguities persist because, with the decline of inflation in the 1990s, research on features of labour contracts generally and indexation in particular has practically ceased. Yet, this new regime of low inflation offers a rich context within which to study labour market ar- 
rangements. While the secular trend in inflation has been downward, the reduction in inflation was, at times, very abrupt, generating considerable nominal uncertainty. In Canada, for instance, the All Items CPI inflation rate was $10.9 \%$ in 1982 and $5.7 \%$ in 1983 and it declined further from $5.6 \%$ in 1991 to $1.5 \%$ in 1992 . As seen below, the implied increase in nominal uncertainty was considerable. A similar argument holds for real uncertainty. The Canada-wide unemployment rate increased from $7.6 \%$ in 1981 to $11 \%$ in 1982 and from $8.1 \%$ in 1990 to $10.4 \%$ in 1991 . The regional effects of these recessions are even more pronounced. Depending on how real uncertainty is measured, ${ }^{3}$ the recessions of the early 1980s and 1990s involved substantial increases in real uncertainty. In combination with the secular inflation context and other relevant variables, changes in nominal and real uncertainty should help researchers identify the forces that operate on labour contracts.

Over the period 1977-2000, ${ }^{4}$ the duration of Canadian wage contracts has doubled. Changes in indexation arrangements have also been substantial see Figure 1 below. It is natural to wonder whether secular and cyclical changes in contract duration and indexation provisions are related to nominal and real shocks. This is all the more likely given that many of the variables mentioned in the first paragraph as determinants of contractual arrangements are agent-specific and, possibly, time-invariant - e.g. risk aversion. The Canadian experience of the last three decades provides a unique opportunity to study the relation between these variables. A larger sample

\footnotetext{
${ }^{3}$ Murphy's (2000) real uncertainty variable is based on the unemployment rate and unusually large unemployment rates would be associated with larger real shocks.

${ }^{4}$ The data set used includes information from 1976-2000. However, first contracts cannot be used and observations from 1976 are lost - see section 4.1.
} 
of contracts than the seminal US studies have relied on, drawn from a longer and richer historical context (1976-2000) than has hitherto been possible, can be used. Attention is directed at contract duration and the elasticity of indexation, using techniques which make it possible to take their interdependence into account as well as to address the distinction between the incidence and intensity of indexation. Time series techniques are used, in a consistent fashion, to model expected inflation as well as nominal and real uncertainty. The results indicate that changes in these variables are largely responsible for the historical evolution of these contractual arrangements.

The remainder of the paper is structured as follows. Section 2 reviews selected aspects of previous theoretical and empirical work on the subjects of contract duration and indexation. Section 3 lays out the econometric model used. Section 4 discusses the contract data as well as information that has been appended. This includes a description of measures of expected inflation as well as nominal and real uncertainty. Section 5 discusses the empirical results, paying particular attention to the role of expected inflation, nominal and real uncertainty. Section 6 offers concluding observations and suggestions for further work.

\section{Some Previous Literature}

In this section, attention is focussed on four critical aspects of the empirical work in this paper with the view to placing the empirical strategy in context, rather than providing an exhaustive survey of earlier work. These aspects concern (i) the generation of measures of expected inflation, nominal and 
real uncertainty, (ii) the distinction between the incidence and intensity of indexation, (iii) the treatment of the interaction between contract duration and indexation, and (iv) the related role of nominal wage adjustment in the model adopted.

A critical aspect of empirical work in this area is the construction of measures of expected inflation and inflation uncertainty. One approach used by a number of authors is to specify a single equation describing inflation which is estimated repeatedly, beginning well-before the period studied and ending at the start of the period of interest. Observations are added as one rolls forward through time. At each point during the period studied, the conditional mean provides estimates of expected inflation and the standard error of estimate, or its squared value, provides a measure of inflation uncertainty. ${ }^{5}$ A second approach is based on Engle's $(1982,1983)$ ARCH or Bollerslev's (1986) Generalised Autoregressive Conditional Heteroscedasticity (GARCH) alternatives to the rolling regression method. These rely on a series' memory and lags, rather than additional regressors, to achieve high descriptive accuracy. While an ARCH model has been used in studies of contract provisions, GARCH models have not. ${ }^{6}$ In this paper, GARCH techniques are used

\footnotetext{
${ }^{5}$ See Christofides and Wilton (1983), Christofides (1985, 1990), Wallace and Blanco (1991) and Wallace (2001), for variations along this theme. Rich and Tracy (2000) argue that, for the US, this measure does not perform as well as their alternative surveyAutoregressive Conditional Heteroscedasticity (ARCH) and structural vector autoregressive (SVAR) measures.

${ }^{6}$ Rich and Tracy (2000) use an ARCH model based on survey data to construct a measure of inflation uncertainty. They also use Gali's (1992) SVAR method, in combination with a rolling window as in Friedman and Kuttner (1996), to construct time-varying measures of nominal and real uncertainty. The relation of these to inflation uncertainy is an
} 
to generate expected inflation and nominal uncertainty. A similar process is used to generate real uncertainty based on deviations of real GDP from trend - see section 4.3 and Appendix 1. A third approach to generating inflation uncertainty relies on survey measures either directly, as in Vroman (1989) and Kanago (1998), or indirectly, as in Rich, Raymond and Butler (1992), to construct needed proxies. However, survey measures are not available for Canada.

It is well known that most contracts contain no COLA clause and that, where one exists, the elasticity of indexation is modest - see Table 1. Thus two conceptually distinct issues, the incidence and the intensity of indexation, need to be considered. Typically, limited dependent variable techniques are used to study the former, ${ }^{7}$ but very few studies $^{8}$ have studied the latter. One approach which combines the study of the incidence and intensity of indexation is the Tobit model which can speak to both issues, a point that has not been exploited in the literature. ${ }^{9}$ The Tobit model is used in this open question which is addressed in Rich, Raymond and Butler (1992).

${ }^{7}$ See, for example, Estenson (1981), Ehrenberg, Danziger and San (1983, 1984), Cousineau, Lacroix and Bilodeau (1983), Hendricks and Kahn (1983, 1985), Ceccheti (1987) and Bils (1990).

${ }^{8}$ Ehrenberg, Danziger and San (1983) use a Tobit model to study the elasticity of indexation in 855 contracts. Card (1986) studies the marginal elasticity of indexation in a truncated sample. Christofides (1990) examines the ex ante average elasticity of indexation using a Tobit model, while Christofides and Stark (1996) consider the ex post average elasticiy of indexation using truncated regression techniques.

${ }^{9}$ See, however, Christofides and Stark (1996). A related issue, which is not pursued in this paper because of the wish to embed the study of indexation in a context where duration is determined simultaneously, is the implied Tobit restriction that variables affect incidence and intensity with the same sign. 
paper.

In principle, all provisions of labour contracts (including those, such as benefit provisions, on which no information is provided in the contract data) are subject to discussion and are determined during contract negotiations. ${ }^{10}$ It is, therefore, natural to think of contract duration and indexation as jointly dependent and the theoretical treatments of Gray (1978) and Ehrenberg, Danziger and San $(1983,1984)$ stress this point. Few studies of these contract provisions have taken this issue on board. ${ }^{11}$ In this paper, we use Amemiya's (1979) model which considers both the jointness of contract duration and indexation and the latent nature of indexation, thereby making it possible to estimate a Tobit model. As noted, the latter can speak to both the incidence and the intensity of indexation.

A final issue that relates to the problems in the previous paragraph, is the treatment of one variable on which information is available, namely noncontingent nominal wage adjustment. It is a major, if not the main, item during contract discussions and its relation to other features of contracts must be considered. An approach that might be followed is that duration, indexation and non-contingent wage adjustment must be modelled simultaneously. This task, allowing for a complete interaction among the variables and addressing the incidence as well as the intensity issue, remains a challenge for this literature. ${ }^{12}$ Earlier Canadian work by Christofides (1990) and

\footnotetext{
${ }^{10}$ For an interesting paper along these lines see Azfar (2000).

${ }^{11}$ Murphy (2000) and Rich and Tracy (2000) deal with indexation incidence only, while Ehrenberg, Danziger and San $(1983,1984)$ use single-equation methods.

${ }^{12}$ Christofides (1990) concludes, on econometric grounds, in favour of a causal structure, where duration and indexation are determined separately from, but do in fact affect, non-
} 
Christofides and Stark (1996) suggests that non-contingent adjustment is affected by but does not affect duration and indexation. ${ }^{13}$ This structure allows for duration and indexation to be considered on their own and it is the approach adopted here.

\section{Econometric Specification}

Given this earlier literature, the duration and indexation equations should be set up as a system, each variable influencing the other as well as being subject to other forces. Duration is measured as a continuous variable and indexation arrangements are captured by the variable Elasticity - see section 4.1. Dropping the time subscripts t, the basic system specified here is

$$
\begin{aligned}
\text { Duration } & =\text { Elasticity }^{*} \cdot \gamma_{1}+X_{1} \beta_{1}+u_{1} \\
\text { Elasticity }^{*} & =\text { Duration } \cdot \gamma_{2}+X_{2} \beta_{2}+u_{2}
\end{aligned}
$$

where the actual value of the elasticity of indexation Elasticity is related to its latent value Elasticity* by

\footnotetext{
contingent adjustment. Murphy (1992) considers the determination of contract duration, noting that wage adjustment and indexation incidence are endogenous variables that must be instrumented. Rich and Tracy (2000) do not consider non-contingent wage adjustment. Finally, Murphy (2000) embeds a Probit, not a Tobit, model in a simultaneous structure that determines, in addition, contract duration and wage adjustment.

${ }^{13}$ Note that the US work by Murphy (2000) also concludes that wage adjustment does not affect COLA incidence; it has a negative effect, significant at the $5 \%$ but not the $1 \%$ level, on contract duration.
} 


$$
\text { Elasticity }=\left\{\begin{array}{cl}
\text { Elasticity }^{*} & \text { if Elasticity } \\
0 & \text { otherwise }
\end{array}\right\}
$$

Equations (1)-(3) present a simultaneous equation system with one of the endogenous variables, Elasticity*, as a latent variable. Amemiya (1974 1979), Nelson and Olson (1977), and Heckman (1977) provide techniques for estimating problems of this general nature. Amemiya (1979) reviews some of these and provides the estimator used here. Write the system of equations (1)-(3) in the form

$$
\begin{aligned}
Y_{1} & =Y_{2}^{*} \gamma_{1}+X_{1} \beta_{1}+u_{1} \\
Y_{2}^{*} & =Y_{1} \gamma_{2}+X_{2} \beta_{2}+u_{2},
\end{aligned}
$$

where $Y_{1}$ is Duration and $Y_{2}^{*}$ is Elasticity, both $T \times 1$ vectors; the $\gamma_{i}, i=$ $\{1,2\}$, are scalars; the $X_{i}$ are $T \times k_{i}$ matrices of explanatory variables; the $\beta_{i}$ are conformable $k_{i} \times 1$ vectors of constant coefficients and the $u_{i}$ are $T \times 1$ vectors of error terms with the usual simultaneous equations properties. Write equations (4) and (5) in their reduced form

$$
\begin{aligned}
Y_{1} & =X \pi_{1}+v_{1} \\
Y_{2}^{*} & =X \pi_{2}+v_{2},
\end{aligned}
$$

where $X$ is $T \times k$ and $\pi_{i}$ is the $k \times 1$ vector of reduced form coefficients for $Y_{i}$. Substitute (6) and (7) into (4) and (5), to obtain 


$$
\begin{aligned}
& \pi_{1}=\pi_{2} \gamma_{1}+J_{1} \beta_{1} \\
& \pi_{2}=\pi_{1} \gamma_{2}+J_{2} \beta_{2}
\end{aligned}
$$

where $J_{i}$, is the $k \times k_{i}$ matrix consisting of zeros and ones in appropriate positions such that $X J_{i}=X_{i}$. Letting $\widehat{\pi}_{i}$ be the OLS estimator of $\pi_{i}$, write equation (8) as

$$
\widehat{\pi}_{1}=\widehat{\pi}_{2} \gamma_{1}+J_{1} \beta_{1}+\left(\widehat{\pi}_{1}-\pi_{1}\right)-\left(\widehat{\pi}_{2}-\pi_{2}\right) \gamma_{1}=\widehat{H} \alpha_{1}+\eta_{1}
$$

where $\widehat{H}=\left(\widehat{\pi}_{2}, J_{1}\right)$ is a $k \times\left(1+k_{1}\right)$ matrix of observables, $\alpha_{1}$ is the $\left(1+k_{1}\right) \times 1$ vector of structural parameters $\alpha_{1}^{\prime}=\left(\gamma_{1}, \beta_{1}^{\prime}\right)$ and $\eta_{1}=\left(\widehat{\pi}_{1}-\pi_{1}\right)-\left(\widehat{\pi}_{2}-\pi_{2}\right) \gamma_{1}$ is an error term.

OLS and GLS estimators of $\alpha_{1}$ based on equation (10) are

$$
\begin{aligned}
\alpha_{1}^{L} & =\left(\widehat{H}^{\prime} \widehat{H}\right)^{-1} \widehat{H}^{\prime} \widehat{\pi}_{1} \\
\alpha_{1}^{G} & =\left(\widehat{H}^{\prime} V_{1}^{-1} \widehat{H}\right)^{-1} \widehat{H}^{\prime} V_{1}^{-1} \widehat{\pi}_{1}
\end{aligned}
$$

where $V_{1}$, the asymptotic variance-covariance matrix of $\eta$, shown by Amemiya (1979) to equal

$$
V_{1}=c\left(X^{\prime} X\right)^{-1}+\gamma_{1}^{2} V_{0}
$$

and the covariance matrices are given by

$$
\begin{aligned}
V\left(\alpha_{1}^{L}\right) & =\left(\widehat{H}^{\prime} \widehat{H}\right)^{-1} \widehat{H}^{\prime} V_{1}^{-1} \widehat{H}\left(\widehat{H}^{\prime} \widehat{H}\right)^{-1} \\
V\left(\alpha_{1}^{G}\right) & =\left(\widehat{H}^{\prime} V_{1}^{-1} \widehat{H}\right)^{-1}
\end{aligned}
$$


In order to implement these estimators, note that $V_{0}$ is the asymptotic variance covariance matrix of $\widehat{\pi}_{2}$, an estimate of which can be obtained from equation (7), $c=\sigma_{1}^{2}-2 \gamma_{1}^{2} \sigma_{12}$ and $\hat{\gamma}_{1}=\widehat{\pi}_{1 i} / \widehat{\pi}_{2 i}$, where $\widehat{\pi}_{1 i}$ is the coefficient in equation (6) on any variable $i$ that appears in $X_{2}$ but not in $X_{1}$ and $\widehat{\pi}_{2 i}$ is the coefficient on this same variable in the reduced form equation for $Y_{2}^{*}$. Further needed estimators are $\widehat{\sigma}_{1}^{2}$, the sum of squared residuals from (6), and $\widehat{\sigma}_{12}^{2}=T^{-1} \sum_{t=1}^{T}\left(y_{2 t} \widehat{v}_{1 t} \widehat{F}_{t}^{-1}\right)$, where $\widehat{v}_{1 t}$ is the $t^{t h}$ element in the vector of OLS residuals from equation (6) and $\hat{F}_{t}=F\left(x_{t}^{\prime} \widehat{\pi}_{2}\right)$, where $F$ is the cumulative normal distribution evaluated at $\hat{Y}_{2 t}=x_{t}^{\prime} \widehat{\pi}_{2}$. The parameters $a_{2}^{\prime}=\left(\gamma_{2}, \beta_{2}^{\prime}\right)$, can be obtained in a similar way. Although the GLS estimator is more complex than the OLS one, it is more efficient and is the approach adopted here. The reduced form equations (6) and (7) are provided for completeness. In addition, results from 2SLS, which ignore the latent nature of the elasticity variable but account for simultaneity, and OLS (duration) or Tobit (indexation), which, in addition to ignoring the latent nature of Elasticity also ignore simultaneity, are presented. These provide a useful sensitivity analysis. The construction and theoretical role of the variables $Y_{1}, Y_{2}$, and $X$ are discussed in the next section.

\section{Data and Sources}

\subsection{The HRDC Data Base}

The contract data used for this study is constructed from electronic records provided by Human Resource Development Canada (HRDC) in Ottawa. Each of the observations represents a legally binding agreement between an 
employer and a bargaining unit and documents many of the provisions of the contract. The data base contains 11885 bargaining agreements reached during the period 1976 through 2000. In order to take into account lagged effects, only observations where at least one prior agreement has been negotiated are considered, leaving 9646 observations for 1977-2000. For these, any variable available for the current contract is also available for the previous contract and is indicated by a p prefix.

The HRDC data contain information on a number of variables, including the main variables under study. Duration is defined by HRDC as the difference between the expiry date and the effective date of the contract. ${ }^{14}$ Descriptive statistics on the variables used are presented in Table 1 - see also Appendix 3. Duration is shown to have a mean of 25.629 months with a standard deviation of 11.499 months. The COLA provisions in contracts are diverse and complex ${ }^{15}$ but they generally describe how the base wage rate should change as some price index evolves. The variable, Elasticity, is defined as the ex post percentage change in the base wage rate brought about by the COLA clause in the contract divided by the percentage change in the CPI over the life of the contract - see section 4.3. As indicated below, the GARCH mechanism, used to generate inflation expectations, is descriptively accurate and supports using the ex post, rather than the ex ante, COLA wage growth on perfect foresight grounds. When the agreement does not contain a COLA clause, Elasticity is set equal to zero. As Table 1 shows, the unconditional mean value of Elasticity is 0.075 with a standard deviation of 0.257

\footnotetext{
${ }^{14}$ See Rich and Tracy (2000) for some of the issues involved in this definition.

${ }^{15}$ For a discussion of some of the issues involved, see Card (1983), Hendricks and Kahn (1985), Kaufman and Woglom (1986), and Ehrenberg, Danziger and San (1984).
} 
while, conditional on Elasticity $>0$, this value for the 1256 contracts involved is 0.579 with a standard deviation of 0.462 . The related variable Cola is set equal to unity when the contract contains a formal COLA clause, even when it was not activated, ${ }^{16}$ and is equal to zero otherwise. Its mean value is 0.192 , indicating that less than $20 \%$ of the contracts contain a COLA clause.

Figure 1 shows Duration, Elasticity and Cola averaged over the contracts that became effective in each of the years 1977-2000. ${ }^{17}$ As can be seen, Duration increased secularly, more than doubling from its 18-month low in 1978 to its 38 month high in 1998. This figure also indicates a secular decline in the incidence (Cola) and intensity (Elasticity) of indexation. The secular trends were, in some instances, interrupted by fairly substantial reversals, as, for example, during 1990-1991, when (i) Cola and Elasticity increased dramatically and (ii) the continuous increase in duration (since 1982) was reversed. There is a very evident link between the incidence and the intensity of indexation. Interactions between Duration and the two indexation variables are more subtle and require conditioning on other variables before they can be discerned. It should be noted that previous-contract values of Duration and Elasticity appear in their respective equations. These variables help identification and, in addition, capture pair-specific fixed effects which

\footnotetext{
${ }^{16}$ There are 1854 contracts for which Cola $=1$ and, for these contracts, the mean value of Elasticity is 0.393 with a standard deviation of 0.467 . The mean for this group is lower than that for the 1256 contracts, since the latter includes only contracts for which the indexation trigger was exceeded and the COLA clause generated a positive wage adjustment.

${ }^{17}$ Note that only four contracts remain for 1977 and that, as these are all indexed, the sample average for the Cola series is used (instead of unity) in order to preserve a reasonable scale in Figure 1. Note, too, the difference between the left and the right scales in Figure 1.
} 
are difficult or impossible to measure - e.g. risk aversion patterns.

Another variable included in the HRDC data base is the nominal base wage rate profile in effect during the contract. Given this, and price information that can be appended (see section 4.3), it is possible to construct the real wage profile as well as the average nominal and real wage rates prevailing over the contract. In this paper, previous contract wages, which are exogenous to the current contract, are used and, as Table 1 shows, the nominal base wage rate Pnomwage is, on average, $\$ 13.312$ with a standard deviation of $\$ 5.469$ over the 9646 contracts. The previous real wage Prealwage has a higher mean as it is deflated by a CPI which has a base of 100 rather late in the sample (in 1992). Another variable in the data base is the number of employees covered by the contract (Employee has a mean of 2138 with a standard deviation of 4644). ${ }^{18}$ Prealwage and Lemployee proxy worker bargaining power and may be expected to increase duration and indexation as these outcomes would provide insurance against unforseen real shocks and inflation respectively. The region (Atlantic, Quebec, Ontario which is the omitted category, Prairie, British Columbia, Territories, and multi-province) and industry (Construction, Transportation, Communications, Utilities, Trade, Education, Health, Services, Other and Manufacturing as the omitted category) in which the firm is located (see Table 1) are included for a variety of reasons. First, labour demand and supply elasticities, which might be expected to vary by region and industry, figure prominently in theoretical

\footnotetext{
${ }^{18}$ The natural logarithm of this variable, Lemployee, is used in the empirical work below. Similar results were obtained using Plemployee because the number of employees across contracts evolves very slowly. These results are available on request.
} 
treatments. In addition, these dummy variables condition on unobservables that might influence bargaining between pairs. Finally, to the extent that these variables are important statistically, their inclusion permits a clearer statistical definition of the role of primary regressors.

\subsection{Other Variables}

Since the effective and expiry dates of each contract are known, it is possible to append further variables to the information for each contract. Among these, the Consumer Price Index (the All Items Index from Statistics Canada, series 100000) is the most important. It allows calculation of Prealwage above, as well as the inflation rate over various points in the contract. In turn, the latter can be used, in the context of GARCH procedures, to generate the expected inflation rate over the life of the contract (Einf) and the associated, time dependent, variance of inflation (Sinfvar), or nominal uncertainty. Similar procedures can be applied to deviations of real GDP from a linear trend to generate the variance profile in the $\mathrm{GARCH}$ process which is used as an indicator of real uncertainty (Sgdpvar). ${ }^{19}$ As indicated in paragraph three, the expected inflation rate has a role to play in some risksharing specifications. There is also evidence in Christofides and Laporte (2002) that, in the presence of menu costs, higher expected inflation leads to more frequent nominal, non-contingent, wage adjustments. The reason is that without more frequent adjustments real wage rates will fluctuate unduly, imposing costs on the bargaining pair. One response is to shorten contract

\footnotetext{
${ }^{19}$ This real uncertainty variable corresponds more closely to real shocks in the real business cycle literature than is the case with measures based on the unemployment rate.
} 
duration and another is more indexation. Thus Einf should affect duration negatively and indexation positively. The role of uncertainty in the literature was discussed in sections 1 and 2. Unless the Danziger (1988) effect dominates, real uncertainty should reduce Duration. Note that productivity-based real uncertainty has an ambiguous effect on the degree of indexation - see Ehrenberg, Danziger and San (1984, Table 1, row 9). Inflation uncertainty should have a positive coefficient in the Elasticity equation.

Another important, dated, variable that has been attached is the indicator of the state of the regional labour market within which the bargaining parties are located. The variable used is the regional unemployment rate, Urate, prevailing at the time the contract became effective. These rates range crosssectionally as well as across time. For instance, in 1988, the unemployment rate was $5.0 \%$ in Ontario and $12.4 \%$ in the Atlantic region; the variation over time is exemplified by the increase in Ontario's unemployment rate to $10.9 \%$ in 1992. Higher unemployment weakens the bargaining power of workers as well as the ability of firms to improve contractual arrangements since it may weaken the demand for its product. It is likely to lead to shorter contracts and to weaken indexation provisions.

\subsection{The Garch Processes}

Following extensive testing downward from more general models, an $\operatorname{AR}(6)$ regression model with a $\operatorname{GARCH}(1,1)$ error process $y_{t}=\gamma_{0}+\gamma_{1} y_{t-1}+$ $\gamma_{2} y_{t-2}+\gamma_{3} y_{t-3}+\gamma_{4} y_{t-4}+\gamma_{5} y_{t-5}+\gamma_{6} y_{t-6}+\varepsilon_{t}$, where $\varepsilon_{t} \mid \Psi_{t-1} \sim N\left(0, h_{t}\right)$ and $h_{t}=\omega+\alpha \varepsilon_{t-1}^{2}+\beta h_{t-1}$, was used to describe $y=\{\pi, g d p\}$, where the inflation rate $\pi_{t}=100 \ln \left(C P I_{t} / C P I_{t-4}\right)$ and the variable $g d p_{t}$ is defined as 
the deviation of real GDP from a linear trend; note that real GDP is Cansim series D15721. ${ }^{20}$ The implied error variance $h_{t}$ is time dependent and proxies nominal and real uncertainty when derived from the $\pi$ and $g d p$ and equations, respectively. Figure 2 shows the actual and predicted values of $\pi_{t}$ and Figure 3 shows the actual and predicted values of $g d p$ over the period 19772000Q3. The fit of the two models is good (see Appendix 1) and the implied nominal and real uncertainty variables are plotted in Figure 4. As can be seen by comparing Figures 2 and 4, the general trend in $\pi_{t}$ is downward with substantial declines in the early 1980s and 1990s. During these periods of substantially reduced inflation, nominal uncertainty increased dramatically. In Figure 3, the deviation of real GDP from trend naturally hovers around zero but real uncertainty, in Figure 4, jumped dramatically during the recessions of the early 1980s and 1990s. These dramatic swings in nominal and real uncertainty can be expected to impact the incidence and intensity of indexation and contract duration. As a by-product of GARCH estimation, it is possible to forecast $\pi_{t}$ one quarter ahead (Einf). Similar procedures were used for Sinfvar and Sgdpvar. These variables were assigned to each contract according to its effective date.

\footnotetext{
${ }^{20}$ Quarterly data availalble over 1946 Q1-2000Q3 $(1992=100)$ were used for the inflation process, while data available over 1961Q1-2000Q3 (1992=100) were used for the real GDP process. In a benchmark study, Crawford and Kasumovich (1996) review different ARCH/GARCH models for the Canadian CPI inflation series; their results show that a relatively simple fixed parameter GARCH model, such as the one used here, can capture the characteristics of Canadian inflation well.
} 


\section{$5 \quad$ Results and Sensitivity Analysis}

\subsection{General Findings from Single Equations}

Tables 2 and 3 present results for contract duration and indexation respectively. In general, the results conform with the expectations in the literature and, considering the cross-sectional nature of the data, the goodness of fit is satisfactory. In this sub-section, the single-equation estimates in column 1, Tables 2 and 3, are considered; simultaneity issues are examined in subsection 5.2. Column 1, Table 2, indicates OLS estimates of the structural duration equation, where Elasticity ${ }^{21}$ replaces the latent variable in equation (1). The coefficient on Elasticity is 3.624 and significant, ${ }^{22}$ suggesting that a fully indexed contract would have duration which is longer than an unindexed contract by nearly four months. There is substantial correlation through time in contract duration as well as significant industry and regional effects. The negative signs on the industry coefficients indicate that the longest contracts are to be found in manufacturing, the omitted class, while the shortest ones are in education. The Atlantic provinces have the longest contracts, longer than the omitted class (Ontario) by 5.576 months. The previous real wage and the logarithm of the number of employees are not significant. The regional unemployment rate has the expected negative sign and is significant. The expected inflation and uncertainty variables all have negative, statistically significant, coefficients which are quantitatively important. Discussion of the importance of these variables is deferred to section 5.3.

\footnotetext{
${ }^{21}$ That is, the OLS method does not take note of the latent nature of the elasticity variable in equation (1).

${ }^{22}$ Unless otherwise stated, two-tailed hypothesis tests are conducted at the $5 \%$ level.
} 
Table 3 presents a set of estimates for the elasticity of indexation. Column 1 reports a structural Tobit equation. The fit of this equation is satisfactory. The interaction between the elasticity of indexation and contract duration, evident in the duration equation, is also present in the Tobit equation of Column 1, Table 3, as is the temporal dependence of indexation on its previous-contract value. It should be stressed that, with the exception of Christofides (1990), no other study attempts to capture the interaction between Duration and Elasticity - for a more extensive discussion of simultaneity, see section 5.2. Significant industry and regional effects are present here as in the duration equation: the most heavily indexed contracts are in manufacturing and in Quebec. Unlike the results in the duration equation, the previous real wage has a role to play and bargaining units involving more employees have contracts which are indexed more heavily. The regional unemployment rate has a coefficient which is significantly negative. The expected inflation and real uncertainty variables have significant, positive and negative respectively, coefficients. However, the nominal uncertainty variable has the expected, positive, coefficient but it is not significant. The role of the expected inflation and uncertainty variables is examined in section 5.3.

Column 1, Table 4, repeats the Tobit coefficients $\gamma_{2}$ and $\beta$ (column 1, Table 3) and presents the marginal effects $F(\bar{z}) \cdot$ coefficient, and the McDonald and Moffitt (1980) decomposition of the marginal effects into the impact of a variable change on (i) the Elasticity above zero, $\partial$ Elasticity* $/ \partial x_{i}$, weighted by the probability, $F(\bar{z})$, of being above zero (this is denoted in Table 4 as the Intensity Effect) and on (ii) the probability of being above the limit, $\partial F(\bar{z}) / \partial x_{i}$, weighted by the expected value of the latent elastic- 
ity E(Elasticity*) (this is denoted in Table 4 as the Incidence Effect). The variable $\bar{z}$ is the standardised mean value of the argument. The figures in columns 3 and 4, Table 4, add up to the complete marginal effect in column 2, Table 4. Columns 5 and 6 , Table 4 , give $\partial$ Elasticity ${ }^{*} / \partial x_{i}$ (the Elasticity* Effect) and $\partial F(\bar{z}) / \partial x_{i}$ (the Probability Effect) respectively. ${ }^{23}$ Table 4 reminds the reader that, relative to the coefficients, the marginal effects are muted. Another point of interest in these calculations is that while the Elasticity and Probability Effects are relatively close in size, their weights in the McDonald and Moffitt (1980) decomposition are not. Since the probability of indexation is considerably lower than the conditional expectation, i.e. $F(\bar{z})<E($ Elasticity $*)$, the impact of changes in variables on the weighted probability of indexation (column 4, Table 4) is larger than their weighted impact on the degree of indexation (column 3, Table 4). For instance, Pelasticity, the variable with the largest marginal effect of 0.0966, has an Incidence Effect of 0.0815 and an Intensity Effect of 0.0151.

\subsection{Simultaneity}

The single equation results above indicate that the theoretical interactions between contract duration and indexation are strongly evident in the data. It is, therefore, important to check how the qualitative and quantitative results in the structural equations change once simultaneity is taken into account. The 2SLS results account for simultaneity but not the latent nature of the index variable, while the Amemiya (1979) method addresses both problems.

\footnotetext{
${ }^{23}$ Note that $F(\bar{z})=0.08, f(\bar{z})=0.1487, E($ Elasticity $)=0.0272$ and $E($ Elasticity $*)=$ 0.3396 .
} 
Looking at contract duration in Table 2 first, the coefficient on the elasticity variable under OLS is bracketed by those for Amemiya (1979) and 2SLS. In the most appropriately estimated Amemiya (1979) specification, the effect of full, relative to no indexation, is almost halved, suggesting that estimates of the structural equation for duration that do not account for simultaneity and the latent variable problem, or (as in 2SLS) account only for the former, overestimate substantially the effect of indexation on duration. Other coefficient estimates are very similar and hypothesis tests are not affected across estimation methods.

The structural equations for indexation, in Table 3, are somewhat more sensitive to how simultaneity is taken into account than is the case in the duration equation. In general, the OLS coefficient estimates and hypothesis test results are similar to those implied by the Amemiya (1979) method. The 2SLS coefficient estimates are often smaller in size but it must be remembered that 2SLS does not account for the latent nature of the elasticity of indexation; the marginal effects for Tobit, in Table 4, are similar in units to the 2SLS ones in Table 3. A notable result concerns the nominal uncertainty variable, which is not significant in the OLS and Amemiya equations but is significant, with the expected sign, in the 2SLS results. McDonald and Moffitt (1980) decompositions for the Amemiya (1979) estimates, similar to those for Tobit results in column 1, Table 4, are very close to those reported in Table 4 and are available in Table A1, Appendix 2.

The reduced form equations used in the Amemiya (1979) estimator are of interest in their own right and appear in column 2, Tables 2 and 3. They show duration and indexation (the latter is estimated as a Tobit) net of the 
interactions between the two variables. These equations confirm the role of the regressors discussed above. Figures 5 and 6 summarise the predictions of the reduced form equations for duration and indexation in Tables 2 and 3 respectively. In the case of indexation, Figure 6 plots the unconditional expected values $E($ Elasticity $)=F(z)\left[\right.$ Duration $\left.\cdot \gamma_{2}+X_{2} \beta_{2}\right]+\sigma f(z)$, where $z=\left[\right.$ Duration $\left.\cdot \gamma_{2}+X_{2} \beta_{2}\right] / \sigma$ and $\sigma$ is the standard deviation of $u_{2} \cdot{ }^{24}$ The predicted values in Figures 5 and 6 track the actual observations well ${ }^{25}$ and are discussed in detail in section 5.3.

In summary, the interaction between contract duration and indexation, which is so important in the theoretical literature, is clearly evident in the estimates presented above. Contract duration is longer when contracts are more heavily indexed and the degree of indexation, in turn, is likely to be greater in long rather than short contracts. When the most appropriate, Amemiya (1979), estimation method is used, the structural equation for the elasticity of indexation is nevertheless similar to the OLS one. However, the structural duration equation entails a coefficient for indexation which is grossly exaggerated when simultaneity and the latent nature of the elasticity variable are ignored. The reduced form equations provide predictions which track the actual observations for duration, the unconditional elasticity of

\footnotetext{
${ }^{24}$ The model can be used to also predict, using $F(\bar{z})$, the probability of indexation. A comparison of this against a dummy variable indicating whether Elasticity $>0$, indicates that the Tobit equation performs well - see Appendix 2, Figure A1. Note that the variable Cola, defined in section 4.1, would lie uniformly above the lines in Figure A1 because of the number of contracts containing COLA clauses which were not activated.

${ }^{25}$ Predictions are made at the individual contract level and are averaged across all contracts that have effective dates in particular years.
} 
indexation and indexation incidence well.

\subsection{Role of Expected Inflation and Uncertainty}

As already noted, Figures 5 and 6 summarise the predictions of the Amemiya (1979) model for duration and indexation respectively. Since the variables of particular interest in this study, namely expected inflation (Einf), nominal (Sinfvar), and real (Sgdpvar) uncertainty are time-dependent, their influence and that of other time-dependent variables, can be seen in these figures. In Figure 5, the predictions track the actual data very well, capturing both the secular increase and the turning points of the early 1980s and 1990s. The secular increase in the predicted values must be due to the right combination of coefficient sign and regressor behaviour through time and the best explanation involves expected inflation. ${ }^{26}$ The five-year average for Einf was lower by 7.72 percentage points at the end of the sample than at the beginning and, multiplied by the coefficient of -0.967 , this produces a predicted increase in contract duration of about 7.46 months over the sample period. Allowing for the long-run amplification of this effect (because of the lagged duration variable) results in a predicted increase in duration of about 11.3 months,

\footnotetext{
${ }^{26}$ Prealwage and Lemployee trend upwards very gently and have positive coefficients which are too small to contribute importantly to the growth in predicted duration. The unemployment rate as well as nominal and real uncertainty are mostly cyclical and hence cannot contribute in a major way to the explanation of the secular increase in duration. It should be noted that the predicted values in Figure 5 reflect the industrial and regional composition of settlements in any particular year. Thus, the discussion in terms of effects through time in this subsection should be thought of as superimposed on an otherwise neutral cross-sectional pattern of settlements.
} 
the approximate amount shown for the actual data in Figure 5.

While the decline in expected inflation appears to be the best single explanation for the secular increase in contract duration, other time-dependent variables contribute valuable detail to the predicted values of Figure 5. For instance, the decline in the predicted duration of some five months between 1990 and 1992 cannot be explained by Einf which declined from $4.49 \%$ in 1990 to $2.95 \%$ in 1992 . However, the substantial decline in actual inflation during this period generated a sharp increase in nominal uncertainty from 0.18 to 0.56 (about 0.38). This, times the coefficient on Sinfvar in the reduced form equation for duration of -5.093 , generates a decline in predicted duration of about two months. The recession also generated considerable real uncertainty, leading to a rise in Sgdpvar from 9.47 to 16.57; this increase, times the coefficient on this variable of -0.198 , contributes another month to the predicted decline in contract duration. Also important during this recession period, was the increase in the unemployment rate from $7.84 \%$ to 11.14\%. Taking the coefficient of -0.34 into account, this 3.3 percentage point increase in Urate would contribute a decrease in predicted duration of about one month. Between them, these short-run effects reduce predicted duration by the amount shown in Figure 5. The other notable decline in predicted duration, which occurred between 1980 and 1982, was largely due to the substantial increase in real uncertainty from 8.83 to 20.76 . This increase accounts $(11.93 \times-0.198)$ for a 2.4 month decrease in contract duration. While expected inflation and nominal uncertainty were reasonably flat during this period (see Figures 2 and 4), the average value of the regional unemployment rate increased from $7.25 \%$ to $10.49 \%$ leading to a 1.1 month $(3.24 \times-0.34)$ 
decrease in predicted duration. Thus, the decline in contract duration during the recession of the early 1980s was driven by real factors alone. The tremendous increase in real uncertainty during 1998 (from 12.25 to 22.11) was also responsible for the small dip in predicted duration in that year, a force which was not reflected in the actual data.

Turning to the behaviour of Elasticity through time, Figure 6 indicates a substantial secular decline which is largely the visual product of outliers in $1977{ }^{27}$ If 1978 is taken as the starting point, Elasticity declined continually from 0.13 to 0.036 in 1998 before increasing to 0.19 in 1999 and falling back to 0.068 in 2000 . A number of secular factors, such as the growth over the sample in Prealwage and Pduration, would suggest (given the positive coefficients of 0.009 and 0.013 respectively) changes in the wrong direction. Thus, again, expected inflation, which declined from $8.26 \%$ in 1978 to $1.48 \%$ in 1998, is left as the only explanation for the secular decline in Elasticity. ${ }^{28}$ In the case of the elasticity of indexation, the uncertainty variables have opposite coefficients so that the impact of the 1990-1992 increase in nominal and real uncertainty tend to cancel out. There is a substantial decrease in Elasticity between 1981 and 1982 which, again, is due to real factors alone. Real uncertainty increased from 13.04 to 20.76 leading to a potential decline in Elasticity of 0.11 points $(7.72 \times-0.014)$ and the regional unemployment rate jumped from $7.01 \%$ to $10.49 \%$ leading to a possible decrease in Elasticity of

\footnotetext{
${ }^{27}$ In 1977 , there are only four observations and these happen to have the rather high conditional elasticity of 0.22 .

${ }^{28}$ Indeed, the predicted decline of 0.37 is considerably larger than what appears in the predictions of Figure 6 because of the forces, seen earlier, which tended to increase the elasticity of indexation.
} 
0.15. During the early 1980s, nominal forces were not substantially at play. The reader is reminded that the actual and predicted values in all figures reflect the industrial and regional composition of the bargaining calendar, so that some cross sectional variation will be superimposed on all the temporal calculations. Such variation appears to be responsible for the predicted increase in Elasticity during 1980 and its decrease in 1995.

\section{Conclusion}

In this paper, a large number of Canadian wage contracts was used to analyse important contract provisions such as their duration and elasticity of indexation. The contracts were arrived at over the period 1976-2000, a period of high, medium and exceptionally low inflation. During this period, the inflation rate declined steadily but not smoothly. The recessions of the early 1980s and 1990s generated not only substantial real but, also, substantial nominal uncertainty. This rich historical context, in combination with the unique dataset assembled by federal authorities, makes it possible to study contracts, using up-to-date time series analysis methods to generate conditioning variables and econometric techniques that account for both simultaneity and the latent nature of the elasticity of indexation. Results on the latter, can, subject to restrictions, be decomposed into effects on the incidence as well as the intensity of indexation. The results obtained generally accord with theory where definite conclusions are warranted and they help guide future theoretical efforts by supplying stylised facts - the results for Canada are similar, where they can be compared, with those obtained 
by Rich and Tracy (2000) for the US. Thus pessimism expressed in earlier work on the correspondence between theory and evidence may, perhaps, be attributed to the short historical period and small number of contracts used in older studies.

A very strong feature of theoretical work in this area is the interdependence between contract duration and indexation, a force which is very evident in the data. Indexed contracts are more likely to be long and long contracts are more likely to be indexed. The quantitative measurement of these cross effects requires the use of techniques which account for both simultaneity and the latent nature of the elasticity of indexation. These effects are established despite the inclusion in the equations of past duration and indexation practices adopted by bargaining pairs. This previous-contract information conditions for difficult-to-measure fixed pair effects and helps clarify the role of other regressors.

Of the variables that may proxy bargaining power, the most reliable is the regional unemployment rate. Increases in this variable reduce contract duration and indexation. Significant regional and industry effects suggest that the longest and most indexed contracts are found in manufacturing and in Quebec and Ontario.

Allowing that the patterns of behaviour in the annual averages plotted in Figures 5 and 6 reflect the bargaining calendar, the model accounts for (i) the dramatic increase in contract duration and the decrease in the elasticity of indexation over the period 1976-2000 and (ii) most of the noteworthy short-run deviations in these variables from trend. As in Rich and Tracy (2000), the expected inflation rate, which declined over the period, is a sig- 
nificant negative force on duration and positive influence on indexation, thus explaining the secular behaviour of both dependent variables. The nominal uncertainty variable has the expected negative influence on duration and its influence on indexation, though consistently positive, has statistical significance which depends on the estimation method adopted. Murphy's (2000, p. 193) conjecture, that the correlation between measures of expected inflation and nominal uncertainty may cloud the influence of each, was checked ${ }^{29}$ and does not appear to account for this weakness. The real uncertainty variable has a negative, significant, coefficient in both the duration and indexation equations. The variation in the uncertainty variables, along with movements in the regional unemployment rate, explain most of the notable short-run fluctuations in contract duration and indexation. In this sense, the hope expressed in the introduction, that a rich historical context may help clarify the role of important variables, may have been justified.

Regretably, the lack of data availability did not permit the use of expectational data from surveys, but our results appear not to be sensitive to the choice of regressors capturing the inflationary environment. An outstanding challenge for this literature is the incorporation of other contractual provisions into a fully simultaneous context. Finally, it would have been desirable to draw on more explicit theoretical treatments of the role of expected inflation in contractual arrangements. Existing theoretical literature tends to downplay the role of this variable. If the results here and in Rich and Tracy (2000) withstand scrutiny, an inductive challenge to theorists will have been

\footnotetext{
${ }^{29}$ When the expected inflation values attached to the 9646 observations were regressed against the values for nominal uncertainty, the $R^{2}$ obtained was 0.083 .
} 
issued. 


\section{Appendix 1: GARCH P rocesses}

Following extensive $L R$ and $A R C H$ tests to determine the optimum lag structure in the main and the error term equations respectively, the speci cations below were selected:

GARCH $(1,1)$ Results for $1 / 4$

$\mathrm{R}^{2}=0.955$

$R^{2}=0.954$

Log-likelihood $=-215.818$

Nobs $=213$

\begin{tabular}{|c|c|c|c|}
\hline Variable & Coe \pm cient & std. dev & t-statistic \\
\hline${ }_{0}^{\circ}$ & 0.145530 & 0.071892 & 2.024282 \\
\hline${ }_{1}$ & 1.391829 & 0.010457 & 133.103751 \\
\hline${ }_{2}$ & -0.241467 & 0.075508 & -3.197900 \\
\hline$\circ_{3}$ & -0.114699 & 0.105339 & -1.088856 \\
\hline$\circ_{4}$ & -0.466283 & 0.104141 & -4.477396 \\
\hline${ }_{5}$ & 0.658432 & 0.095240 & 6.913366 \\
\hline${ }_{6}^{\circ}$ & -0.259567 & 0.055737 & -4.656993 \\
\hline$!$ & 0.020127 & 0.016180 & 1.243971 \\
\hline- & 0.816233 & 0.078517 & 10.395657 \\
\hline ® & 0.132984 & 0.066642 & 1.995508 \\
\hline \multicolumn{4}{|l|}{ and } \\
\hline \multicolumn{4}{|c|}{ GARCH $(1,1)$ Results for gdpt } \\
\hline \multicolumn{4}{|c|}{$R^{2}=0.812$} \\
\hline \multicolumn{4}{|l|}{$R^{2}=0.804$} \\
\hline
\end{tabular}




\begin{tabular}{|c|c|c|c|}
\hline \multicolumn{4}{|c|}{ Log-likelihood $=-407.638$} \\
\hline \multicolumn{4}{|c|}{ Nobs $=153$} \\
\hline \multicolumn{4}{|c|}{ 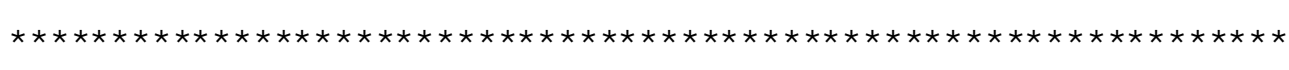 } \\
\hline Variable & Coe \pm cient & std. dev. & t-statistic \\
\hline${ }^{\circ} 0$ & 0.111780 & 0.272105 & 0.410797 \\
\hline${ }^{\circ}$ & 1.188145 & 0.084186 & 14.113348 \\
\hline${ }^{\circ} 2$ & -0.359293 & 0.134628 & -2.668788 \\
\hline${ }^{\circ} 3$ & 0.209213 & 0.130434 & 1.603972 \\
\hline${ }^{\circ} 4$ & -0.220799 & 0.125637 & -1.757439 \\
\hline${ }_{5}^{\circ}$ & -0.038757 & 0.118359 & -0.327456 \\
\hline${ }^{\circ} 6$ & 0.045305 & 0.074749 & 0.606090 \\
\hline$!$ & 3.348482 & 3.102360 & 1.079334 \\
\hline- & 0.486113 & 0.308306 & 1.576719 \\
\hline (R) & 0.264855 & 0.135348 & 1.956850 \\
\hline
\end{tabular}


A ppendix 2: Table A 1, Figure A 1 
Table A1

Decompostion of Amemiya Results for Elasticity

\begin{tabular}{|c|c|c|c|c|c|c|}
\hline Variable & Coefficient & $\begin{array}{l}\text { Marginal } \\
\text { Effect }\end{array}$ & $\begin{array}{l}\text { Intensity } \\
\text { Effect }\end{array}$ & \begin{tabular}{|l|} 
Incidence \\
Effect
\end{tabular} & $\begin{array}{l}\text { Elasticity } \\
\text { Effect }\end{array}$ & $\begin{array}{l}\text { Probability } \\
\text { Effect }\end{array}$ \\
\hline Intercept & -2.2930 & -0.1927 & -0.0309 & -0.1619 & -0.3671 & -0.4722 \\
\hline Duration & 0.0280 & 0.0024 & 0.0004 & 0.002 & 0.0045 & 0.0058 \\
\hline Prealwage & 0.0120 & 0.0010 & 0.0002 & 0.0008 & 0.0019 & 0.0025 \\
\hline Pelasticity & 1.1950 & 0.1004 & 0.0161 & 0.0844 & 0.1913 & 0.2461 \\
\hline Natres & -0.0090 & -0.0008 & -0.0001 & -0.0006 & -0.0014 & -0.0019 \\
\hline Constr & -0.4690 & -0.0394 & -0.0063 & -0.0331 & -0.0751 & -0.0966 \\
\hline Transp & -0.1270 & -0.0107 & -0.0017 & -0.009 & -0.0203 & -0.0262 \\
\hline Commun & -0.1150 & -0.0097 & -0.0015 & -0.0081 & -0.0184 & -0.0237 \\
\hline Utils & -0.1530 & -0.0129 & -0.0021 & -0.0108 & -0.0245 & -0.0315 \\
\hline Trade & -0.5180 & -0.0435 & -0.007 & -0.0366 & -0.0829 & -0.1067 \\
\hline Educat & -0.2500 & -0.0210 & -0.0034 & -0.0176 & -0.04 & -0.0515 \\
\hline Health & -0.3180 & -0.0267 & -0.0043 & -0.0224 & -0.0509 & -0.0655 \\
\hline Service & -0.4800 & -0.0403 & -0.0065 & -0.0339 & -0.0768 & -0.0989 \\
\hline Others & -0.3310 & -0.0278 & -0.0045 & -0.0234 & -0.053 & -0.0682 \\
\hline Atlantic & -0.0810 & -0.0068 & -0.0011 & -0.0057 & -0.013 & -0.0167 \\
\hline Que & 0.1160 & 0.0097 & 0.0016 & 0.0082 & 0.0186 & 0.0239 \\
\hline Prairie & -0.0590 & -0.0050 & -0.0008 & -0.0042 & -0.0094 & -0.0122 \\
\hline $\mathrm{BC}$ & -0.2400 & -0.0202 & -0.0032 & -0.0169 & -0.0384 & -0.0494 \\
\hline Terri & 0.1130 & 0.0095 & 0.0015 & 0.008 & 0.0181 & 0.0233 \\
\hline Mprov & -0.2230 & -0.0187 & -0.003 & -0.0157 & -0.0357 & -0.0459 \\
\hline Lemployee & 0.0730 & 0.0061 & 0.001 & 0.0052 & 0.0117 & 0.015 \\
\hline Urate & -0.0350 & -0.0029 & -0.0005 & -0.0025 & -0.0056 & -0.0072 \\
\hline Einf & 0.0820 & 0.0069 & 0.0011 & 0.0058 & 0.0131 & 0.0169 \\
\hline Sinfvar & 0.1770 & 0.0149 & 0.0024 & 0.0125 & 0.0283 & 0.0365 \\
\hline Sgdpvar & -0.0080 & -0.0007 & -0.0001 & -0.0006 & -0.0013 & -0.0016 \\
\hline$F(z)^{a}$ & 0.084 & & & & & \\
\hline$f(z)^{b}$ & 0.1543 & & & & & \\
\hline E(Elasticity) ${ }^{c}$ & 0.0288 & & & & & \\
\hline E(Elasticity*) & 0.3428 & & & & & \\
\hline
\end{tabular}

${ }^{\mathrm{a}} \mathrm{F}$ is the cumulative standard normal density function evaluated at $\mathrm{z}$, where $z=\bar{x} \hat{\beta} / \hat{\sigma}$

${ }^{\mathrm{b}} \mathrm{f}$ is the standard normal probability density function.

${ }^{c}$ Mean value of estimated unconditional elasticity, where E(Elasticity*) denotes the mean value of the conditional variable - see section 5.1. 


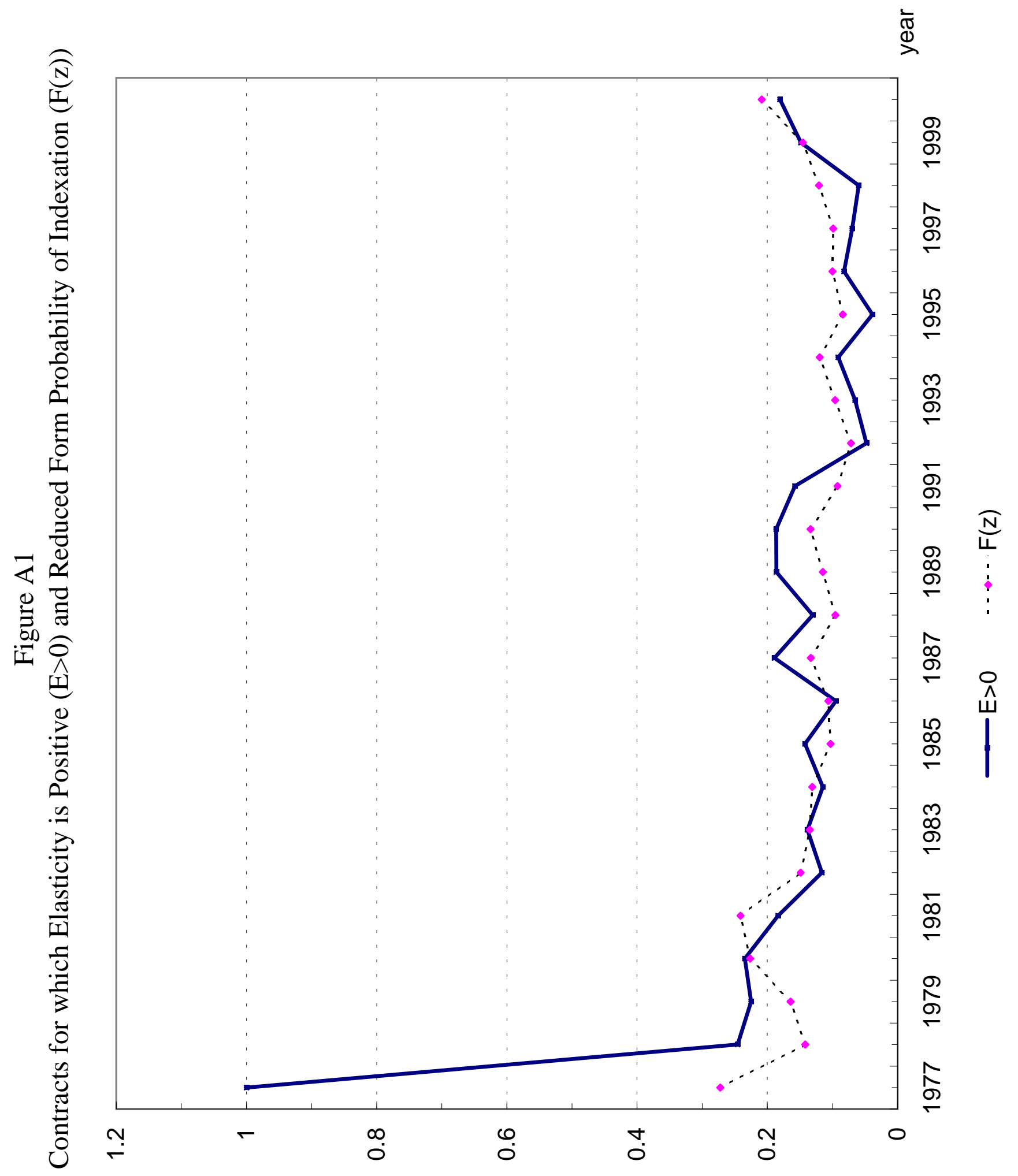




\section{Appendix 3: Data Construction}

The following variables are drawn from the HRDC database:

Duration: Di ßerence between expiry and eßective date (rounded to the nearest whole month).

Cola: A dummy variable which equals 1 if the contract contains any one of four COLA clause types and is equal to zero otherwise.

Elasticity: The percentage change of CO LA wage adjustment divided by the percentage change in the $\mathrm{CPI}$, over the duration of the contract.

Pelasticity: Elasticity for the previous contract.

Prealwage: The nominal wage rate divided by the CPI at the end of previous agr eement.

Industry: Dummy variables generated using the Statistics Canada 1970 Standard Industrial Classi ${ }^{-}$cation code.

Region: Atlantic refers to Newfoundland, Prince Edward Island, Nova Scotia and New Brunswick; Prairie refers to Manitoba, Saskatchewan and A lberta: Territories refers to Yukon and North West Territories and multiprovince to contracts which apply to workplaces in a number of provinces.

Lemployee: The natural logarithm of the number of employees in the bargaining unit.

U rate - Quarterly unemployment rate matched by province at settlement date.

The following variables are generated from GARCH processes:

Einf: Expected in ${ }^{\circ}$ ation generated, from a GARCH $(1,1)$ process describing the in ${ }^{\circ}$ ation rate. It is the aver age $\mathrm{in}^{\circ}$ ation rate forecast one quarter ahead. It is assigned according to the eßect ive date of the contract. B ased on 
the All Items Consumer Price Index (Statistics Canada P100000, 1992=100).

Sinfvar: $1 n^{\circ}$ ation uncertainty generated as the one quarter ahead forecast of the conditional variance from a GARCH $(1,1)$ process describing the in ${ }^{\circ}$ ation rate. It is assigned to each contract according to the erective date. Sgdpvar: Real uncertainty gener ated as the one quarter ahead forecast of the conditional variance from a GARCH $(1,1)$ process describing the deviation of real GDP (Statistics Canada D15721, billions of 1992 dollars) from an estimated linear trend. It is assigned to each contract according to the e Rective date. 


\section{R eferences}

[1] Azfar, 0. (2000) 'Innovation in labor contracts: on theadoption of pro- $t$ sharing in Canadian labor contracts.' ', Industrial R elations, 39, 291-312.

[2] Azariadis, C. (1978) 'Escalator clauses and the allocation of cyclical risks.' , J ournal of E conomic Theory, 18, 119-155.

[3] A memiya, T . (1974). 'Multivariate regression and simult aneous equation models when the dependent variables are truncated normal.', Econometrica, 42, 999-1012.

[4] A memiya, T. (1979). 'T he estimation of a simultaneous-equation Tobit model.' ', International E conomic R eview, 20, 169-81.

[5] B arcena-R uiz, J.C. and Campo, M.L. (2000) 'Short-term or long-term labor contracts.', Labour E conomics, 7, 249-60.

[6] Bils, M . (1990) 'Indexation and contract length in unionized US manufacturing.' ' T he Hoover Institution, Stanford University W PE-90-18.

[7] Bollerslev, T. (1986) 'Generalized autoregressive conditional heteroscedasticity.', J ournal of E conometrics, 31, 5-59.

[8] Canzoneri, M .B. (1980) 'Labor contracts and monetary policy.' , J ournal of M onetary Economics, 6, 241-225.

[9] Card, D. (1983) 'Cost of living escalators in major union contracts.', Industrial and Labor Relations Review, 37, 34-48. 
[10] Card, D. (1986) 'An empirical model of wage indexation provisions in uni on contracts.' , J ournal of Political E conomy, 94, S144 - S175.

[11] Ceccheti, S.G. (1987) 'Indexation and incomes policy: a study of wage adjustment in unionized manufacturing.', J ournal of Labor E conomics, 5, 391-412.

[12] Christo- des, L.N. (1985), 'T he impact of controls on wage contract duration.', The E conomic J ournal, 95, 161 - 168.

[13] Christo' des, L.N. (1990) 'T he interaction between indexation, contract duration and non-contingent wage adjustment.', Economica, 59, 395 409.

[14] Christo' des, L.N. and Laporte, A (2002) 'Menu costs, nominal wage revisions, and intracontract wage behavior.', Industrial Relations, 41, 287-303.

[15] Christo- des, L.N. and Stark, A.(1996) 'The incidence and intensity of wage indexation: an empirical analysis.', Applied Economics, 28, 233 -240 .

[16] Christo' des, L.N. and Wilton, D.A. (1983) 'The determinants of contract length: an empirical analysis based on Canadian micro data.', J ournal of M onetary E conomics, 12, 309 -319.

[17] Cousineau, J., Lacroix, R . and Bilodeau, D. (1983) 'T he determination of escalator clauses in collective agreements.', T he Review of Economics and Statistics, 65, 196-202. 
[18] Crawford, A. and Kasumovich, M. (1996) 'Does Inªtion Uncertainty Vary with the Level of $\mathrm{In}^{\circ}$ ation?', Bank of Canada Working Paper 96-9.

[19] Danziger, L. (1988) 'Real shocks, e \pm cient risk sharing, and the duration of labor contracts.', Quarterly J ournal of E conomics, 103, 435 - 440.

[20] Dye, Ronald A . (1985) 'Optimal length of labor contracts.', I nternational E conomic R eview, 26, 251 -270.

[21] Engle, R. F . ( 1982) 'Autoregressive conditional heteroskedasticity with estimates of the variance of United Kingdom in ${ }^{\circ}$ ation.', Econometrica 50, 987-1007.

[22] Ehrenberg, R. G., Danziger, L. and San, G. (1983) 'Cost-of-living adjustment clauses in union contracts: a summary of results.' , J ournal of Lab or Economics, 1, 212-245.

[23] Ehrenberg, R. G., Danziger L. and San, G. (1984) 'Cost-of-Living adjustment clauses in union contracts. ', In R esearch in Labor E conomics, Ronald G. Ehrenberg (ed.), (Greenwich, Connecticut, J AI Press), 1 63.

[24] Estenson, D. (1981) 'R elative price variability and indexed labor agreements. ', Industrial Relations, 20, 870-884.

[25] Friedman, B .M. and Kuttner, K.N. (1996) 'A price target for US monetary policy? Lessons from the experience with a money growth target.', B rookings $P$ apers on Economic A ctivity, 1, 77-125. 
[26] Gali, J. (1992) 'How well does the IS-LM model 't postwar US data?', Quarterly J ournal of Economics, 107, 709-738.

[27] Gray, J. A . (1976) 'Wage indexation: a macroeconomic approach.', J ournal of M onetary E conomics 2, 221 - 235.

[28] Gray, J. A. (1978) 'On indexation and contract length.', J ournal of Political E conomy, 86, 1 - 18.

[29] Heckman, J. (1978) 'Dummy endogenous variables in a simultaneous equation system.' ' E conometrica 46, 931-959.

[30] Hendricks, W. E., and Kahn, L. E. (1983), 'Cost-of-living clauses in uni on contracts: determinants and eßects.', Industrial and Labor R elations R eview, 36, 447 - 460.

[31] Hendricks, W. E. and K ahn, L. E. (1985) Wage determination in the United States: Cola and Uncola. (Cambridge, MA, Ballinger Press).

[32] Kanago, B. (1998) 'T he relation between contract duration and in ${ }^{\circ}$ ation uncertainty: further evidence.' , J ournal of M acroeconomics, 20, 811-819.

[33] Kaufman, R.T . and Woglom, G. (1986) 'T he degree of indexation in major US union contracts.' , Industrial and Lab or R elations Review, 39, 439-448.

[34] M cDonald, J . F. and M o \pm tt, R. A . (1980) 'T he uses of Tobit analysis.', The Review of E conomics and Statistics, LSII, 318-321. 
[35] Murphy, K. J . (1992) 'Determinants of contract duration in collective bargaining agreements.' , Industrial and Labor Relations Review, 45, 352 $-365$.

[36] Murphy, K. J . (2000) 'W hat eßect does uncertainty have on the length of labor contracts?' Labour Economics, 7, 181-201.

[37] Nelson, F. and O Ison, L. (1978) 'Speci' cation and estimation of a simultaneous equation model with limited dependent variables.', International E conomic R eview, 19, 68-95-709.

[38] Rich, R.W., Raymond, J.E. and Butler, J.S. (1992) 'The relationship between forecast dispersion and forecast uncertainty: evidence from a survey data ARCH model. ', J ournal of A pplied E conometrics, 7, 131-148

[39] Shavell, S. (1976) 'Sharing risks of deferred payment.', J ournal of Political E conomy, 84, 161-168.

[40] Tracy, J and R ich, R. (2000) 'Uncertainty and labor contract duration.', NBER working paper 7731, 1-48.

[41] Vroman, S. (1989) 'In ${ }^{\circ}$ ation uncertainty and contract duration.', Review of Economics and Statistics, 71, 677 - 681.

[42] Wallace, F.H. and Blanco, H. (1991) 'The erects of real and nominal shocks on union- ${ }^{-}$rm contract duration.' , J ournal of M onetary E conomics, 27, 316-380.

[43] Wallace, F.H. (2001) 'T he eßects of shock size and type on labor-contract duration.' , J ournal of Labor E conomics, 19, 658-681. 
Table 1

Summary Statistics ${ }^{\mathrm{a}}$

\begin{tabular}{|c|c|c|c|}
\hline Variable & Description & Mean & Std Dev \\
\hline Duration & contract length in months & 25.629 & 11.499 \\
\hline Cola & dummy variable: contract contains Cola & 0.192 & 0.394 \\
\hline Elasticity & elasticity of indexation & 0.075 & 0.257 \\
\hline $\mathrm{E} \mid \mathrm{E}>0$ & conditional elasticity of indexation & 0.579 & 0.462 \\
\hline Pcola & dummy variable: previous contract contains Cola & 0.206 & 0.404 \\
\hline Pelasticity & the intensity of indexation for previous contract & 0.085 & 0.269 \\
\hline Pdur & contract duration (previous contract) & 23.892 & 9.906 \\
\hline Pnomwage & nominal wage (previous contract) & 13.308 & 5.470 \\
\hline Prealwage & real wage (previous contract) & 0.157 & 0.048 \\
\hline Natres & dummy variable: natural resource & 0.027 & 0.163 \\
\hline Manuf & dummy variable: manufacturing ${ }^{\text {b }}$ & 0.195 & 0.396 \\
\hline Constr & dummy variable: construction & 0.051 & 0.220 \\
\hline Transp & dummy variable: transportation & 0.082 & 0.274 \\
\hline Commun & dummy variable: communication & 0.036 & 0.186 \\
\hline Utils & dummy variable: utility & 0.028 & 0.165 \\
\hline Trade & dummy variable: trade & 0.042 & 0.200 \\
\hline Educat & dummy variable: education & 0.251 & 0.434 \\
\hline Health & dummy variable: health care & 0.085 & 0.278 \\
\hline Service & dummy variable: service & 0.032 & 0.176 \\
\hline Others & dummy variable: other sector & 0.171 & 0.377 \\
\hline Atlantic & dummy variable: Atlantic region & 0.071 & 0.257 \\
\hline Que & dummy variable: Quebec & 0.150 & 0.358 \\
\hline Ont & dummy variable: Ontario ${ }^{b}$ & 0.365 & 0.481 \\
\hline Prairie & dummy variable: Prairie provinces & 0.170 & 0.376 \\
\hline $\mathrm{BC}$ & dummy variable: British Columbia & 0.115 & 0.319 \\
\hline Terri & dummy variable: Territories & 0.005 & 0.069 \\
\hline Mprov & dummy variable: muti-province contracts & 0.124 & 0.330 \\
\hline Employee & number of of employees covered by contract & 2138.250 & 4644.470 \\
\hline Lemployee & natural logarithm of employee & 7.073 & 0.902 \\
\hline Urate & quarterly regional unemployment rate & 9.361 & 2.762 \\
\hline Einf & expected inflation estimated from GARCH & 4.446 & 3.053 \\
\hline Sinfvar & nominal uncertainty & 0.296 & 0.119 \\
\hline Sgdpvar & real uncertainty & 12.918 & 4.634 \\
\hline
\end{tabular}

${ }^{a}$ Based on 9646 observations for which previous contract information is available. They are drawn from 1977-2000. The original sample consists of 11885 constracts drawn from 1976-2000.

${ }^{\mathrm{b}}$ These categories constitute the omitted class. 


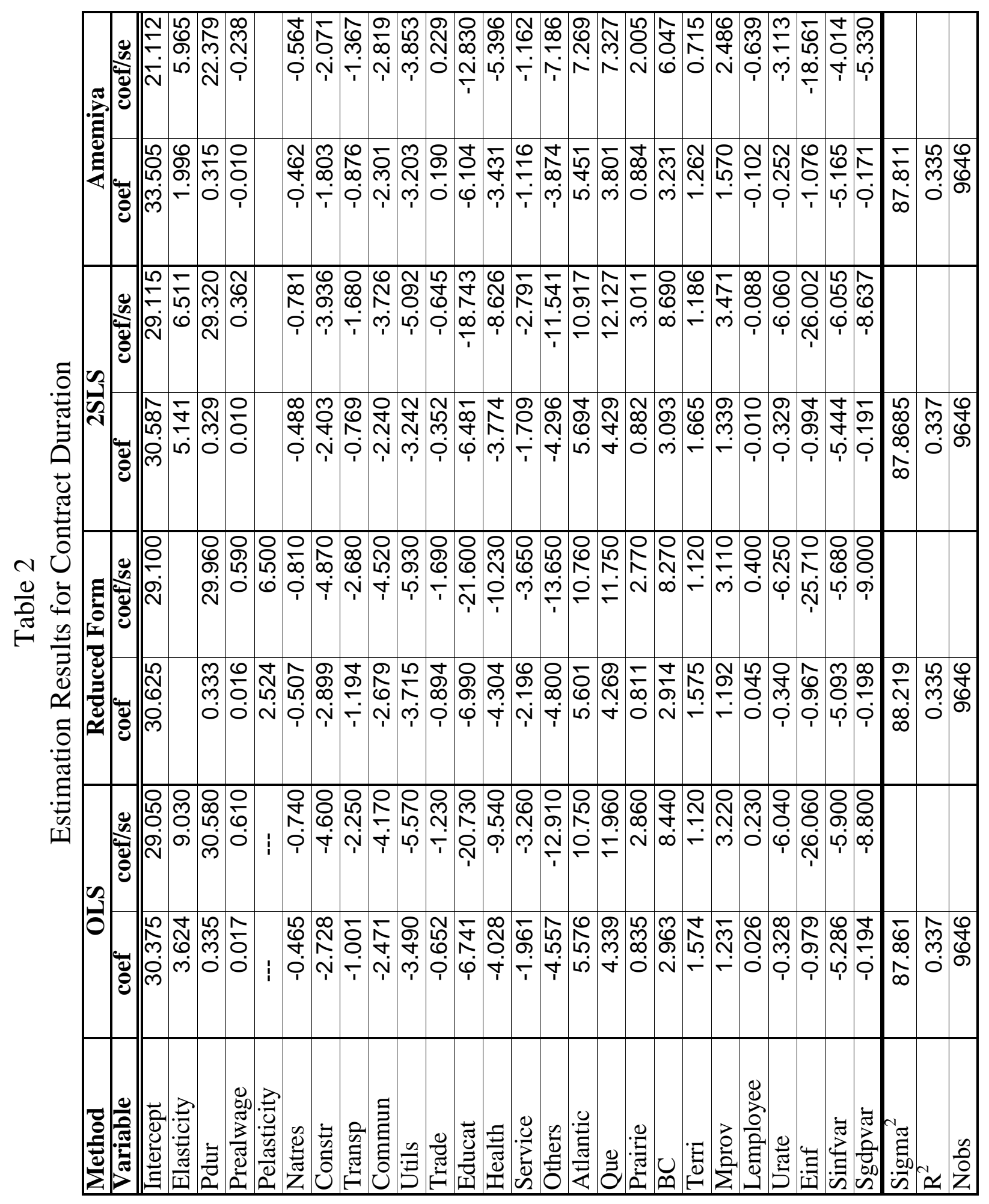




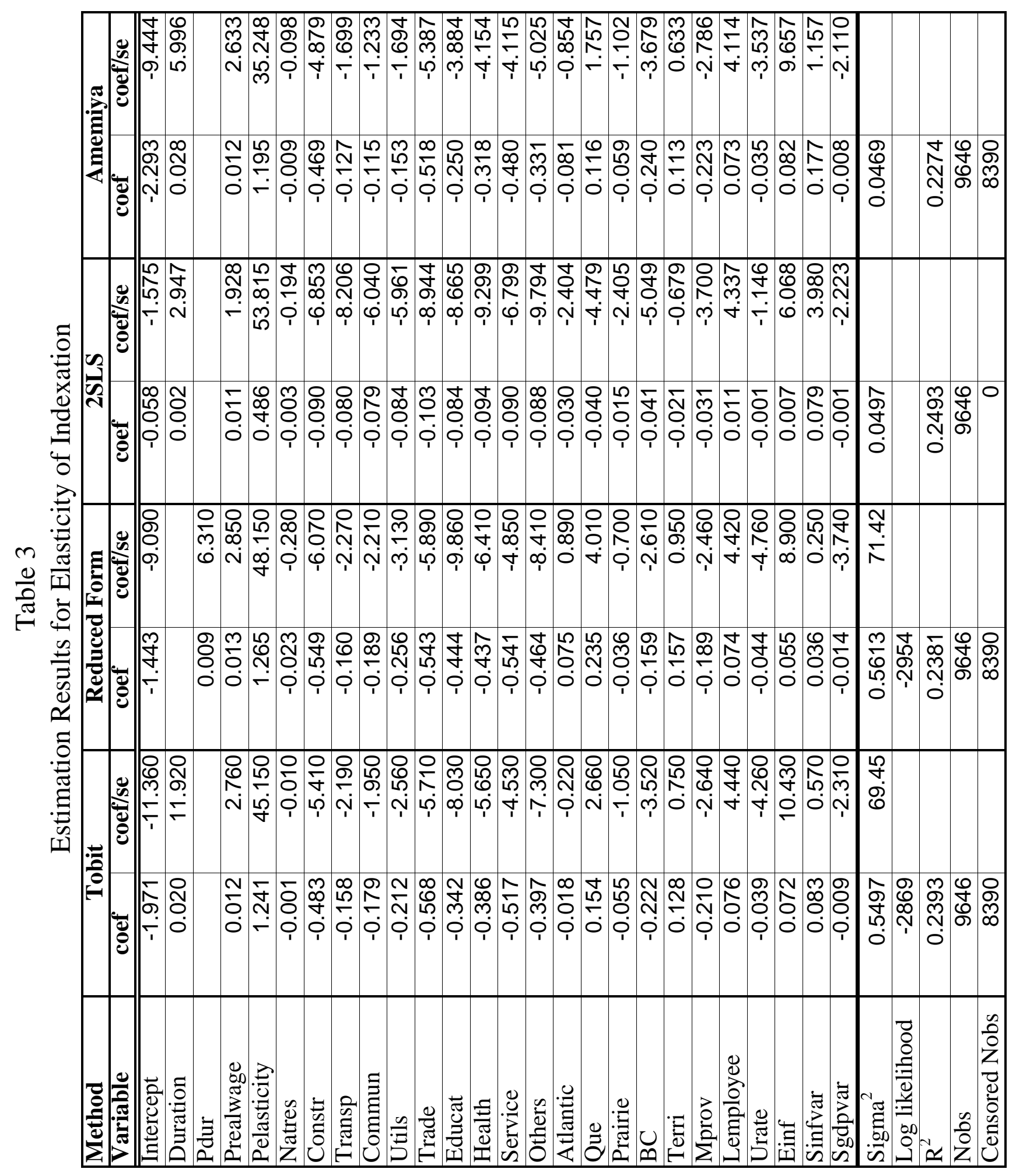


Table 4

Decomposition of the Tobit Results for Elasticity

\begin{tabular}{|c|c|c|c|c|c|c|}
\hline Variable & Coefficient & $\begin{array}{l}\text { Marginal } \\
\text { Effect }\end{array}$ & $\begin{array}{l}\text { Intensity } \\
\text { Effect }\end{array}$ & $\begin{array}{l}\text { Incidence } \\
\text { Effect }\end{array}$ & $\begin{array}{l}\text { Elasticity } \\
\text { Effect }\end{array}$ & $\begin{array}{l}\text { Probability } \\
\text { Effect }\end{array}$ \\
\hline Intercept & -1.9710 & -0.1534 & -0.0240 & -0.1294 & -0.3083 & -0.3872 \\
\hline Duration & 0.0200 & 0.0016 & 0.0002 & 0.0013 & 0.0031 & 0.0039 \\
\hline Prealwage & 0.0120 & 0.0009 & 0.0001 & 0.0008 & 0.0019 & 0.0024 \\
\hline Pelasticity & 1.2410 & 0.0966 & 0.0151 & 0.0815 & 0.1941 & 0.2438 \\
\hline Natres & -0.0010 & -0.0001 & 0.0000 & -0.0001 & -0.0002 & -0.0002 \\
\hline Constr & -0.4830 & -0.0376 & -0.0059 & -0.0317 & -0.0755 & -0.0949 \\
\hline Transp & -0.1580 & -0.0123 & -0.0019 & -0.0104 & -0.0247 & -0.0310 \\
\hline Commun & -0.1790 & -0.0139 & -0.0022 & -0.0118 & -0.0280 & -0.0352 \\
\hline Utils & -0.2120 & -0.0165 & -0.0026 & -0.0139 & -0.0332 & -0.0416 \\
\hline Trade & -0.5680 & -0.0442 & -0.0069 & -0.0373 & -0.0888 & -0.1116 \\
\hline Educat & -0.3420 & -0.0266 & -0.0042 & -0.0225 & -0.0535 & -0.0672 \\
\hline Health & -0.3860 & -0.0300 & -0.0047 & -0.0253 & -0.0604 & -0.0758 \\
\hline Service & -0.5170 & -0.0402 & -0.0063 & -0.0340 & -0.0809 & -0.1016 \\
\hline Others & -0.3970 & -0.0309 & -0.0048 & -0.0261 & -0.0621 & -0.0780 \\
\hline Atlantic & -0.0180 & -0.0014 & -0.0002 & -0.0012 & -0.0028 & -0.0035 \\
\hline Que & 0.1540 & 0.0120 & 0.0019 & 0.0101 & 0.0241 & 0.0302 \\
\hline Prairie & -0.0550 & -0.0043 & -0.0007 & -0.0036 & -0.0086 & -0.0108 \\
\hline $\mathrm{BC}$ & -0.2220 & -0.0173 & -0.0027 & -0.0146 & -0.0347 & -0.0436 \\
\hline Terri & 0.1280 & 0.0100 & 0.0016 & 0.0084 & 0.0200 & 0.0251 \\
\hline Mprov & -0.2100 & -0.0163 & -0.0026 & -0.0138 & -0.0328 & -0.0412 \\
\hline Lemployee & 0.0760 & 0.0059 & 0.0009 & 0.0050 & 0.0119 & 0.0149 \\
\hline Urate & -0.0390 & -0.0030 & -0.0005 & -0.0026 & -0.0061 & -0.0077 \\
\hline Einf & 0.0720 & 0.0056 & 0.0009 & 0.0047 & 0.0113 & 0.0141 \\
\hline Sinfvar & 0.0830 & 0.0065 & 0.0010 & 0.0055 & 0.0130 & 0.0163 \\
\hline Sgdpvar & -0.0090 & -0.0007 & -0.0001 & -0.0006 & -0.0014 & -0.0018 \\
\hline$F(z)^{a}$ & 0.08 & & & & & \\
\hline$f(z)^{b}$ & 0.1487 & & & & & \\
\hline$E\left(\right.$ Elasticity $^{c}$ & 0.0272 & & & & & \\
\hline E(Elasticity*) & 0.3396 & & & & & \\
\hline
\end{tabular}

${ }^{a} \mathrm{~F}$ is the cumulative standard normal density function evaluated at $\mathrm{z}$, where $z=\bar{x} \hat{\boldsymbol{\beta}} / \hat{\boldsymbol{\sigma}}$

${ }^{\mathrm{b}} \mathrm{f}$ is the standard normal probability density function.

${ }^{c}$ Mean value of estimated unconditional elasticity, where E(Elasticity*) denotes the mean value of the conditional variable - see section 5.1 . 


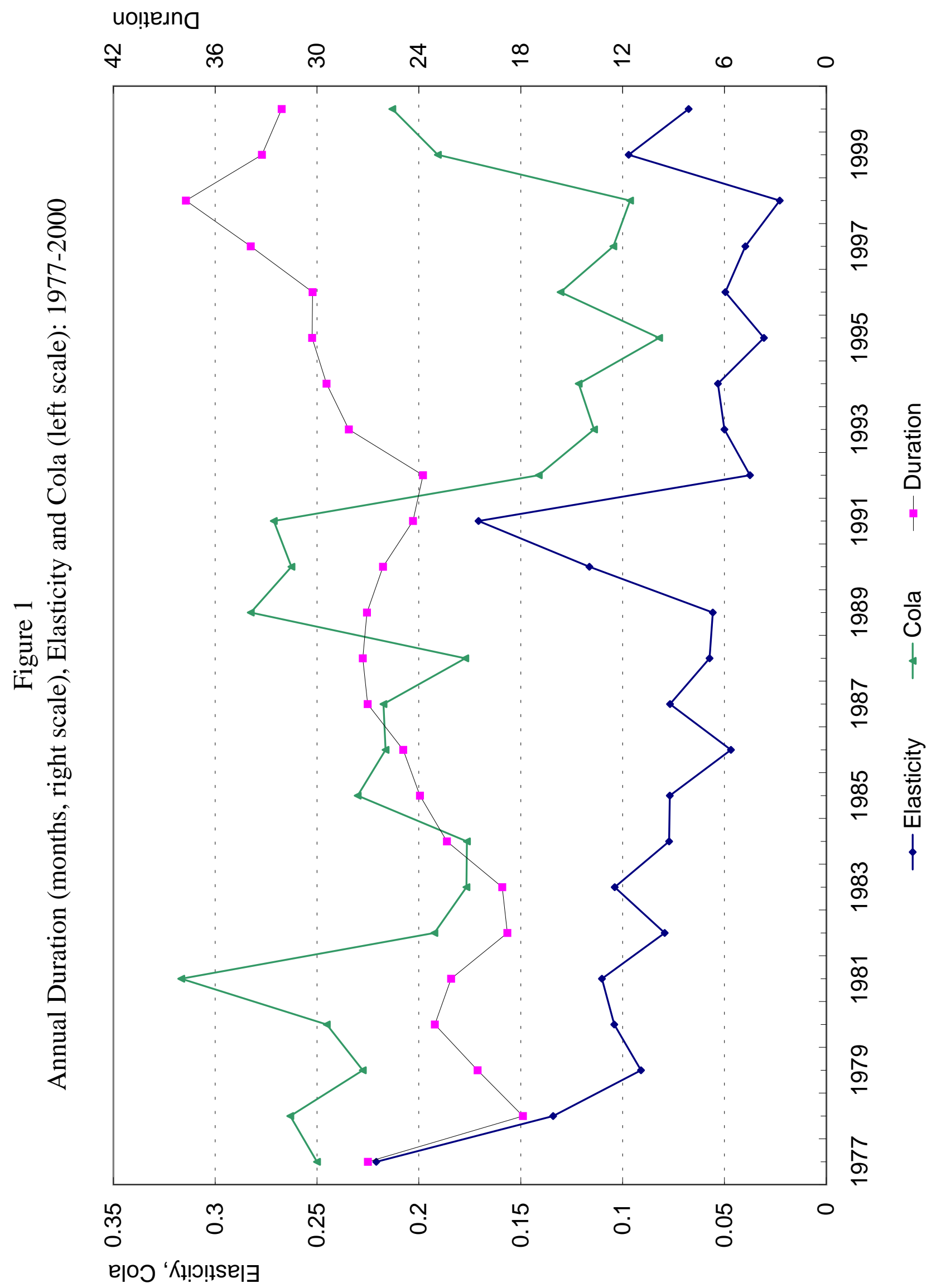


ঠั

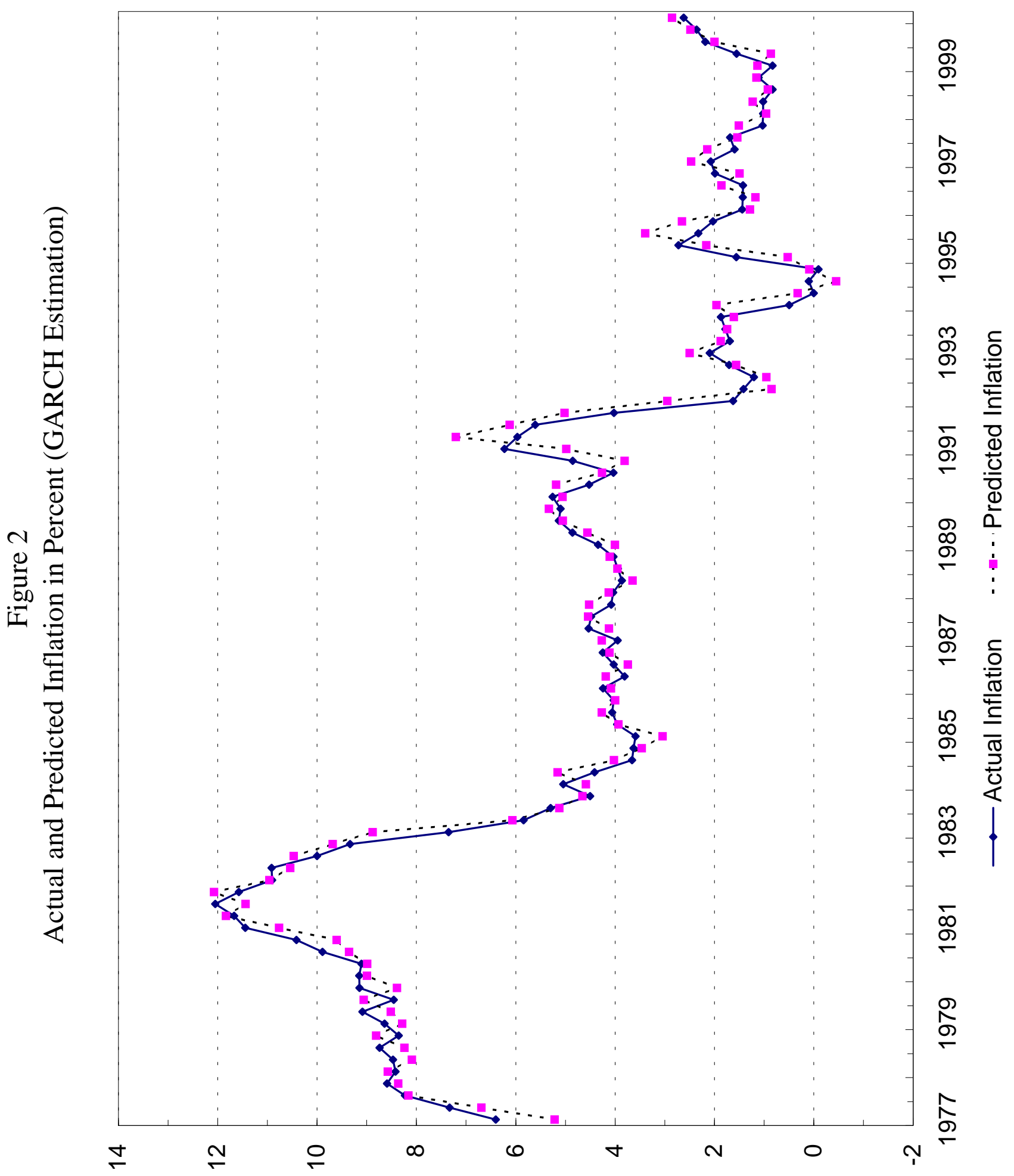




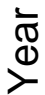

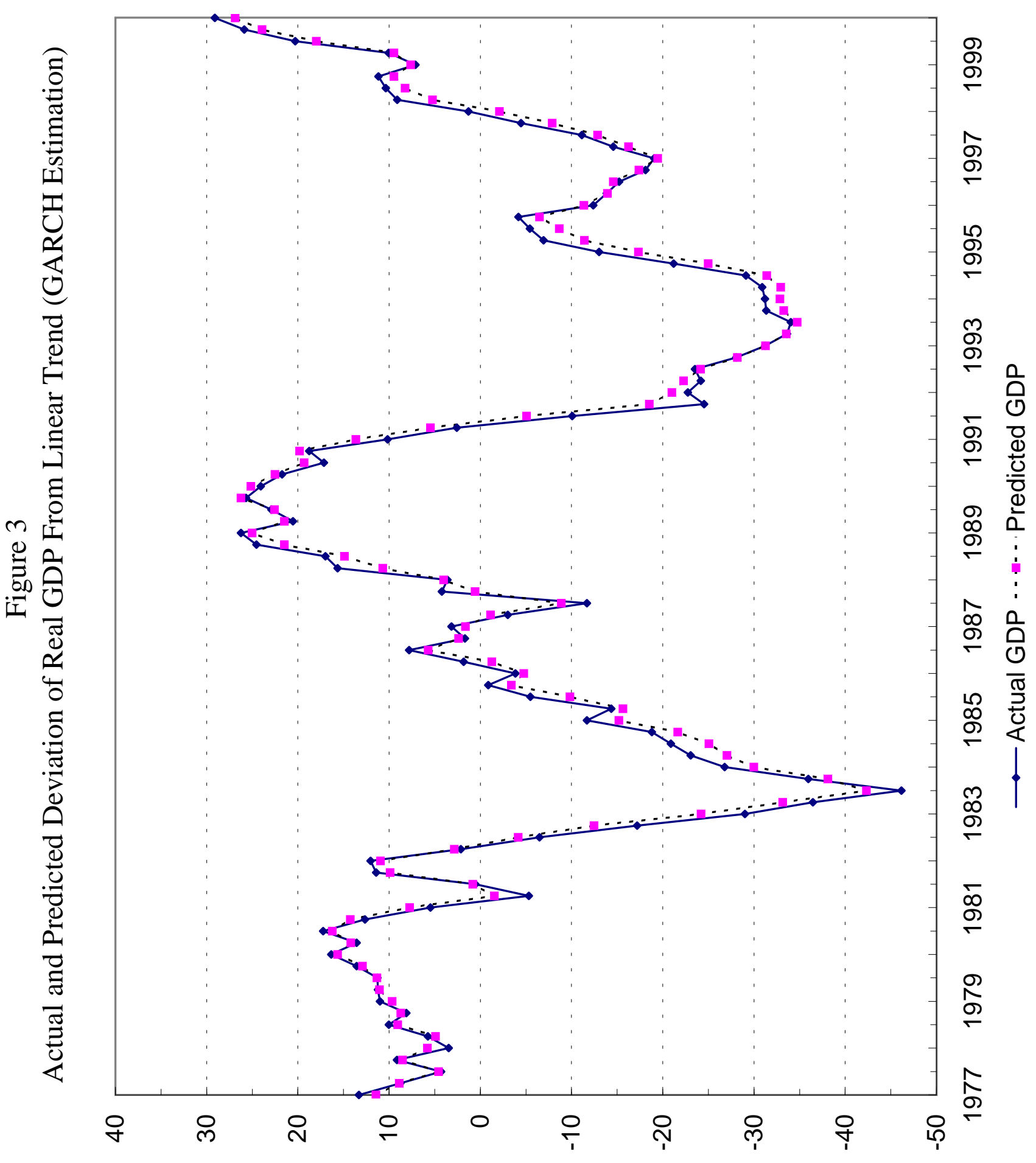

sıe||op ट66 ᄂ to suo!॥!g 


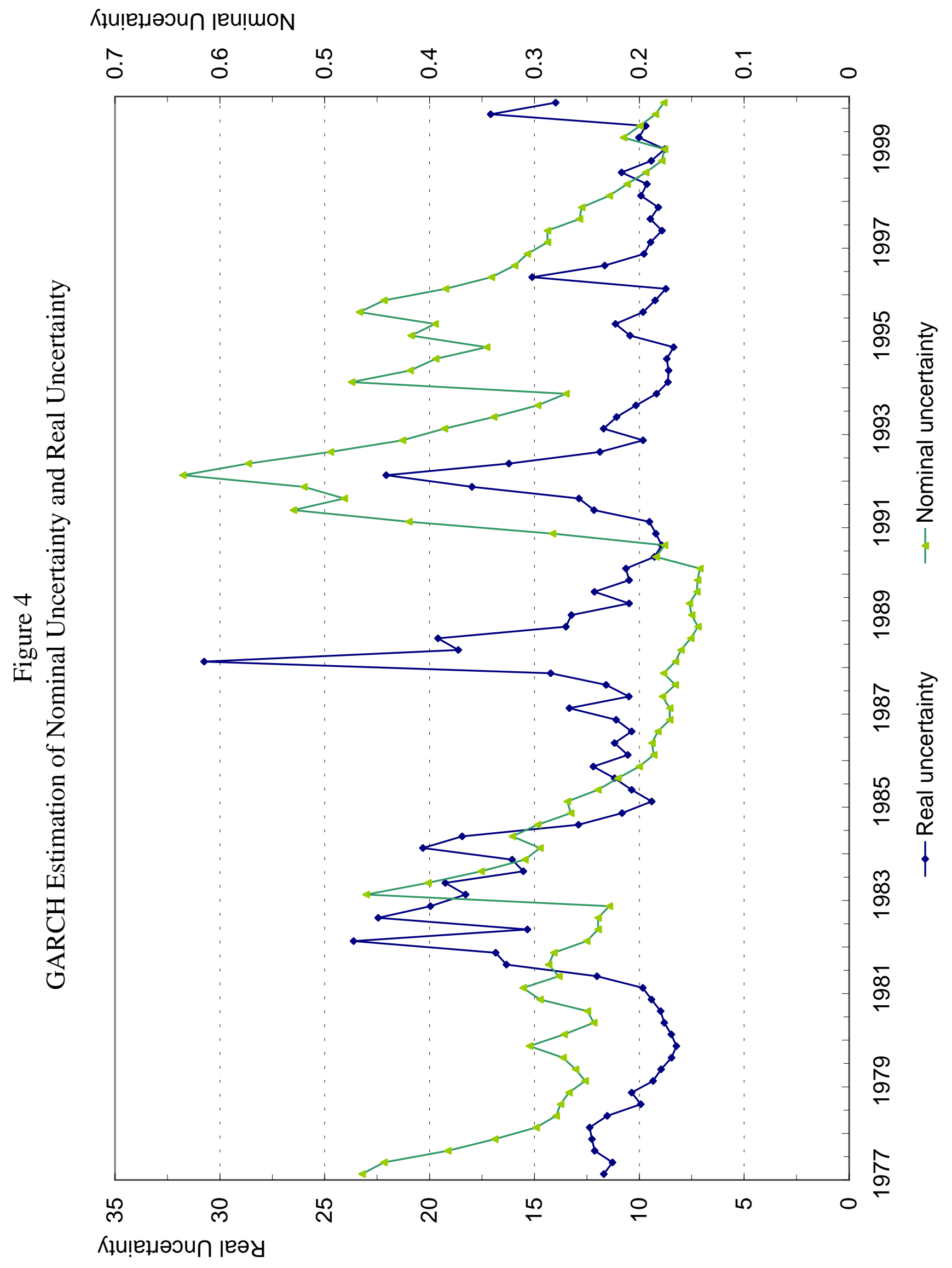


$\stackrel{\bar{\varpi}}{\searrow}$

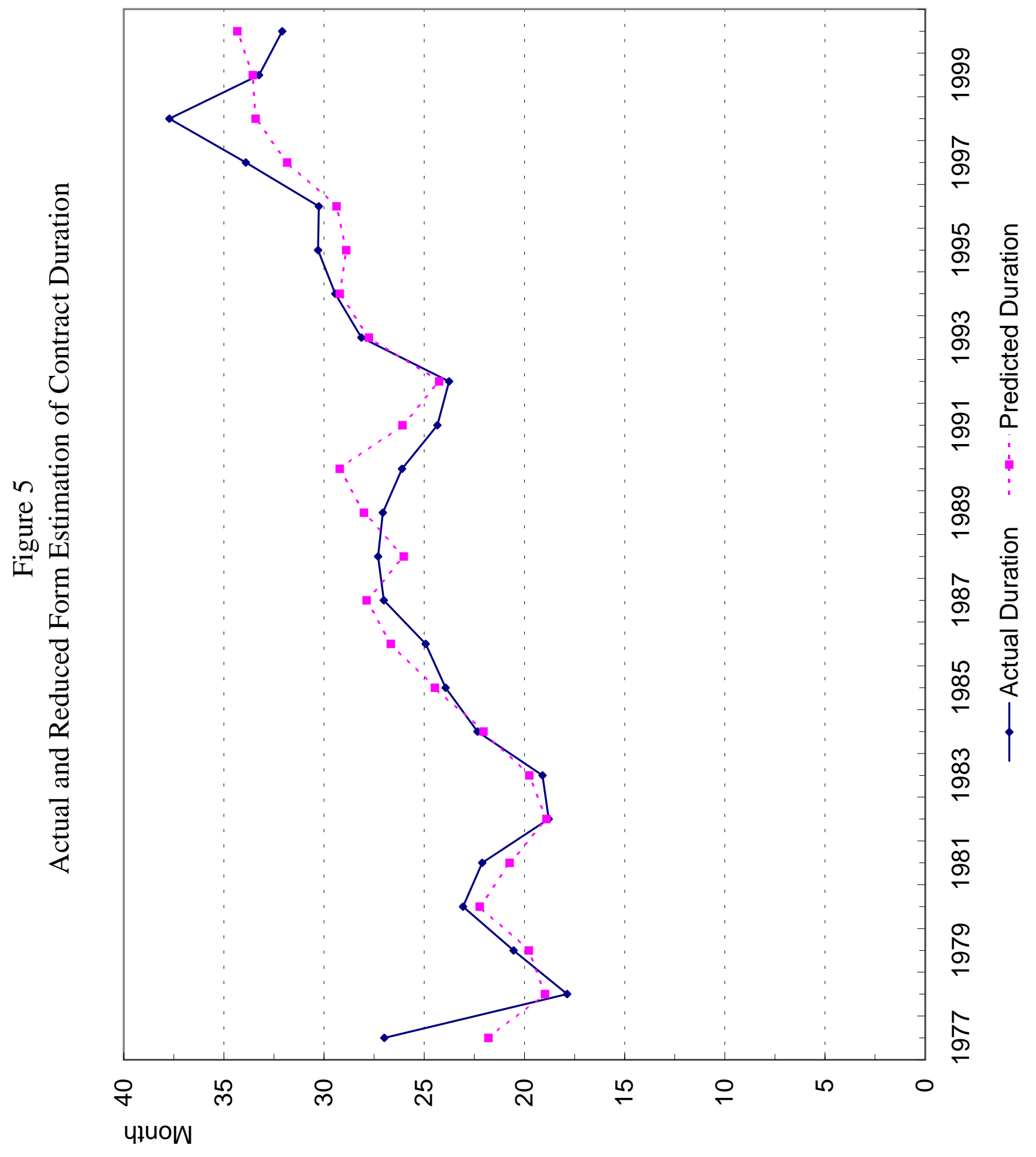


힌

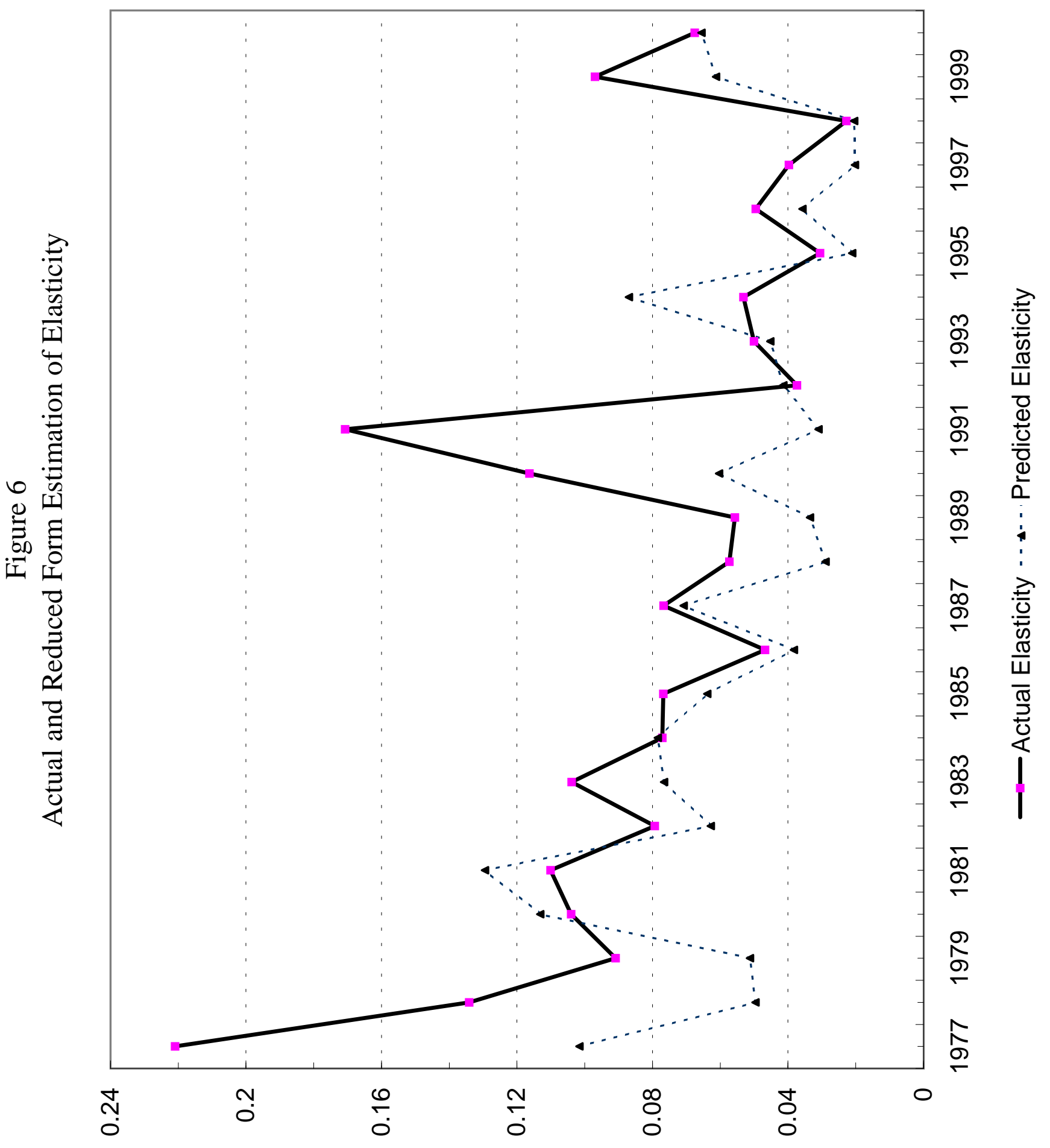




\title{
CESifo Working Paper Series
}

\author{
(for full list see www.cesifo.de)
}

929 Paolo M. Panteghini and Guttorm Schjelderup, Competing for Foreign Direct Investments: A Real Options Approach, April 2003

930 Ansgar Belke, Rainer Fehn, and Neil Foster, Does Venture Capital Investment Spur Employment Growth?, April 2003

931 Assar Lindbeck, Sten Nyberg, and Jörgen W. Weibull, Social Norms and Welfare State Dynamics, April 2003

932 Myrna Wooders and Ben Zissimos, Hotelling Tax Competition, April 2003

933 Torben M. Andersen, From Excess to Shortage - Recent Developments in the Danish Labour Market, April 2003

934 Paolo M. Panteghini and Carlo Scarpa, Irreversible Investments and Regulatory Risk, April 2003

935 Henrik Jacobsen Kleven and Claus Thustrup Kreiner, The Marginal Cost of Public Funds in OECD Countries. Hours of Work Versus Labor Force Participation, April 2003

936 Klaus Adam, George W. Evans, and Seppo Honkapohja, Are Stationary Hyperinflation Paths Learnable?, April 2003

937 Ulrich Hange, Education Policy and Mobility: Some Basic Results, May 2003

938 Sören Blomquist and Vidar Christiansen, Is there a Case for Public Provision of Private Goods if Preferences are Heterogeneous? An Example with Day Care, May 2003

939 Hendrik Jürges, Kerstin Schneider, and Felix Büchel, The Effect of Central Exit Examinations on Student Achievement: Quasi-experimental Evidence from TIMSS Germany, May 2003

940 Samuel Bentolila and Juan F. Jimeno, Spanish Unemployment: The End of the Wild Ride?, May 2003

941 Thorsten Bayindir-Upmann and Anke Gerber, The Kalai-Smorodinsky Solution in Labor-Market Negotiations, May 2003

942 Ronnie Schöb, Workfare and Trade Unions: Labor Market Repercussions of Welfare Reform, May 2003

943 Marko Köthenbürger, Tax Competition in a Fiscal Union with Decentralized Leadership, May 2003 
944 Albert Banal-Estañol, Inés Macho-Stadler, and Jo Seldeslachts, Mergers, Investment Decisions and Internal Organisation, May 2003

945 Kaniska Dam and David Pérez-Castrillo, The Principal-Agent Matching Market, May 2003

946 Ronnie Schöb, The Double Dividend Hypothesis of Environmental Taxes: A Survey, May 2003

947 Erkki Koskela and Mikko Puhakka, Stabilizing Competitive Cycles with Distortionary Taxation, May 2003

948 Steffen Huck and Kai A. Konrad, Strategic Trade Policy and Merger Profitability, May 2003

949 Frederick van der Ploeg, Beyond the Dogma of the Fixed Book Price Agreement, May 2003

950 Thomas Eichner and Rüdiger Pethig, A Microfoundation of Predator-Prey Dynamics, May 2003

951 Burkhard Heer and Bernd Süssmuth, Cold Progression and its Effects on Income Distribution, May 2003

952 Yu-Fu Chen and Michael Funke, Labour Demand in Germany: An Assessment of NonWage Labour Costs, May 2003

953 Hans Gersbach and Hans Haller, Competitive Markets, Collective Decisions and Group Formation, May 2003

954 Armin Falk, Urs Fischbacher, and Simon Gächter, Living in Two Neighborhoods Social Interactions in the LAB, May 2003

955 Margarita Katsimi, Training, Job Security and Incentive Wages, May 2003

956 Clemens Fuest, Bernd Huber, and Jack Mintz, Capital Mobility and Tax Competition: A Survey, May 2003

957 Edward Castronova, The Price of 'Man' and 'Woman': A Hedonic Pricing Model of Avatar Attributes in a Synthetic World, June 2003

958 Laura Bottazzi and Marco Da Rin, Financing Entrepreneurial Firms in Europe: Facts, Issues, and Research Agenda, June 2003

959 Bruno S. Frey and Matthias Benz, Being Independent is a Great Thing: Subjective Evaluations of Self-Employment and Hierarchy, June 2003

960 Aaron Tornell and Frank Westermann, Credit Market Imperfections in Middle Income Countries, June 2003 
961 Hans-Werner Sinn and Wolfgang Ochel, Social Union, Convergence and Migration, June 2003

962 Michael P. Devereux, Measuring Taxes on Income from Capital, June 2003

963 Jakob de Haan, Jan-Egbert Sturm and Bjørn Volkerink, How to Measure the Tax Burden on Labour at the Macro-Level?, June 2003

964 Harry Grubert, The Tax Burden on Cross-Border Investment: Company Strategies and Country Responses, June 2003

965 Kirk A. Collins and James B. Davies, Measuring Effective Tax Rates on Human Capital: Methodology and an Application to Canada, June 2003

966 W. Steven Clark, Using Micro-Data to Assess Average Tax Rates, June 2003

967 Christopher Heady, The 'Taxing Wages' Approach to Measuring the Tax Burden on Labour, June 2003

968 Michael P. Devereux and Alexander Klemm, Measuring Taxes on Income from Capital: Evidence from the UK, June 2003

969 Bernhard Eckwert and Itzhak Zilcha, The Effect of Better Information on Income Inequality, June 2003

970 Hartmut Egger and Josef Falkinger, The Role of Public Infrastructure for Firm Location and International Outsourcing, June 2003

971 Dag Morten Dalen and Trond E. Olsen, Regulatory Competition and Multi-national Banking, June 2003

972 Matthias Wrede, Tax Deductibility of Commuting Expenses and Residential Land Use with more than one Center, June 2003

973 Alessandro Cigno and Annalisa Luporini, Scholarships or Student Loans? Subsidizing Higher Education in the Presence of Moral Hazard, June 2003

974 Chang Woon Nam, Andrea Gebauer and Rüdiger Parsche, Is the Completion of EU Single Market Hindered by VAT Evasion?, June 2003

975 Michael Braulke and Giacomo Corneo, Capital Taxation May Survive in Open Economies, July 2003

976 Assar Lindbeck, An Essay on Welfare State Dynamics, July 2003

977 Henrik Jordahl and Luca Micheletto, Optimal Utilitarian Taxation and Horizontal Equity, July 2003

978 Martin D. D. Evans and Richard K. Lyons, Are Different-Currency Assets Imperfect Substitutes?, July 2003 
979 Thorsten Bayindir-Upmann and Frank Stähler, Market Entry Regulation and International Competition, July 2003

980 Vivek Ghosal, Firm and Establishment Volatility: The Role of Sunk Costs, Profit Uncertainty and Technological Change, July 2003

981 Christopher A. Pissarides, Unemployment in Britain: A European Success Story, July 2003

982 Wolfgang Buchholz, Richard Cornes, and Wolfgang Peters, On the Frequency of Interior Cournot-Nash Equilibria in a Public Good Economy, July 2003

983 Syed M. Ahsan and Panagiotis Tsigaris, Choice of Tax Base Revisited: Cash Flow vs. Prepayment Approaches to Consumption Taxation, July 2003

984 Campbell Leith and Jim Malley, A Sectoral Analysis of Price-Setting Behavior in US Manufacturing Industries, July 2003

985 Hyun Park and Apostolis Philippopoulos, Choosing Club Membership under Tax Competition and Free Riding, July 2003

986 Federico Etro, Globalization and Political Geography, July 2003

987 Dan Ariely, Axel Ockenfels and Alvin E. Roth, An Experimental Analysis of Ending Rules in Internet Auctions, July 2003

988 Paola Conconi and Carlo Perroni, Self-Enforcing International Agreements and Domestic Policy Credibility, July 2003

989 Charles B. Blankart and Christian Kirchner, The Deadlock of the EU Budget: An Economic Analysis of Ways In and Ways Out, July 2003

990 M. Hasham Pesaran and Allan Timmermann, Small Sample Properties of Forecasts from Autoregressive Models under Structural Breaks, July 2003

991 Hyun Park, Apostolis Philippopoulos and Vangelis Vassilatos, On the Optimal Size of Public Sector under Rent-Seeking competition from State Coffers, July 2003

992 Axel Ockenfels and Alvin E. Roth, Late and Multiple Bidding in Second Price Internet Auctions: Theory and Evidence Concerning Different Rules for Ending an Auction, July 2003

993 Pierre Salmon, The Assignment of Powers in an Open-ended European Union, July 2003

994 Louis N. Christofides and Chen Peng, Contract Duration and Indexation in a Period of Real and Nominal Uncertainty, July 2003 